NBER WORKING PAPER SERIES

\title{
POLITICAL CONTRIBUTION CAPS AND LOBBY FORMATION: THEORY AND EVIDENCE
}

\author{
Allan Drazen \\ Nuno Limão \\ Thomas Stratmann \\ Working Paper 10928 \\ http://www.nber.org/papers/w10928
}

\author{
NATIONAL BUREAU OF ECONOMIC RESEARCH \\ 1050 Massachusetts Avenue \\ Cambridge, MA 02138 \\ November 2004
}

We thank Stephanie Aaronson, Phil Keefer, Andrew Lyon, Peter Murrell, Yona Rubinstein, Robert Schwab, and participants at seminars at the University of Maryland and Tel Aviv University, the 2004 Public Choice Conference, the 2004 Pier Conference on Political Economics, and the 2004 INSIE Conference for useful comments. The usual disclaimer applies. The views expressed herein are those of the author(s) and do not necessarily reflect the views of the National Bureau of Economic Research.

(c) 2004 by Allan Drazen, Nuno Limão, and Thomas Stratmann. All rights reserved. Short sections of text, not to exceed two paragraphs, may be quoted without explicit permission provided that full credit, including (C) notice, is given to the source. 
Political Contribution Caps and Lobby Formation: Theory and Evidence Allan Drazen, Nuno Limão, and Thomas Stratmann

NBER Working Paper No. 10927

November 2004

JEL No. D7, H0, P16

\begin{abstract}
The perceived importance of "special interest group" money in election campaigns motivates widespread use of caps on allowable contributions. We present a bargaining model in which putting a cap that is not too stringent on the size of the contribution a lobby can make improves its bargaining position relative to the politician, thus increasing the payoff from lobbying. Such a cap will therefore increase the equilibrium number of lobbies when lobby formation is endogenous. Caps may then also increase total contributions from all lobbies, increase politically motivated government spending, and lower social welfare. We present empirical evidence from U.S. states consistent with the predictions of the model. We find a positive effect on the number of PACs formed from enacting laws constraining PAC contributions. Moreover, the estimated effect is nonlinear, as predicted by the theoretical model. Very stringent caps reduce the number of PACs, but as the cap increases above a threshold level, the effect becomes positive. Contribution caps in the majority of US states are above this threshold.
\end{abstract}

\author{
Allan Drazen \\ Department of Economics \\ University fo Maryland \\ College Park, MD 20742 \\ Nuno Lamão \\ Department of Economics \\ University fo Maryland \\ College Park, MD 20742 \\ Thomas Stratman \\ Center for the Study of Public Choice \\ George Mason University \\ MSN 1D3 - Carow Hall \\ 4400 University Drive \\ Fairfax, VA 22030
}




\section{Introduction}

One of the leading criticisms of the political system in the United States and many other countries is the influence of money on politics, and, more specifically, the influence of special interest groups (SIGs) on policies and elections via their ability to contribute money to politicians. Concern with the effect of money is not new ${ }^{1}$, but the magnitude of contributions, particularly what is known as "soft money", now makes this concern especially central to assessments of how democracy works.

A crucial aspect of political finance reform is thus regulating and limiting contributions that can be made to politicians. Many countries have contribution limits. ${ }^{2}$ The most obvious regulation is a cap on the size of contributions made by individual lobbies. ${ }^{3}$ Contribution caps are often expected to lower the influence that SIGs have, possibly lowering the total amount of SIG money in politics and thus generating policy outcomes that are more desirable from a social welfare perspective.

This reasoning ignores the possible effect of contribution caps on the bargaining position of existing SIGs relative to the government, as well as the effect of caps on the incentives for new SIGs to organize. In this paper, we present a simple optimizing model where SIGs and politicians bargain over an economic policy that the politician can implement in exchange for contributions. In this framework, binding contribution caps can improve a lobby's bargaining position and increase the return to lobbying. ${ }^{4}$ Intuitively the cap allows a lobby to credibly offer a smaller contribution for any given level of the policy for which it is bargaining. ${ }^{5}$

The strengthening of lobbies' bargaining position implies that binding caps can lead to an increase in the number of lobbies formed. We derive conditions under which this endogenous increase in the

\footnotetext{
${ }^{1}$ Craig (1978, p. 506) notes that Gustav Stresemann, the leading political figure in Weimar Germany in the late 1920 s, felt that legislation limiting political contributions might be necessary in that period to curb the influence of vested interests.

${ }^{2}$ For example, France, India, Israel, Italy, Japan, Mexico, Russia, Spain, Taiwan, Turkey, United States. See www.aceproject.org.

${ }^{3}$ Such limits are often controversial, as, for example, limiting freedom of speech. The U.S. in 2003 implemented important federal campaign finance reform, which was immediately challenged, and subsequently upheld by the U.S. Supreme Court in December 2003.

${ }^{4}$ Ansolabehere, et al. (2003) argue that caps on PAC contributions at the federal level in the U.S. are generally not binding (though there are PACs for which caps are binding). At the state level, caps are far more often binding, perhaps because they are at a lower level. We were able to collect data for a number of recent state gubernatorial races. In the Florida gubernatorial race of $1998,90 \%$ of the contributions for Jeb Bush that we could identify as coming from PACs were at the cap of $\$ 500$, while $80 \%$ of PAC contributions for the challenger Mackay were at the cap. In Montana in 1996, $97 \%$ of contributions for the winner Racicot that we could identify as coming from PACs were at the cap of $\$ 400$; in Kansas in 1998 , over $50 \%$ of PAC contributions to the winner Graves were at the cap of $\$ 2000$. (In each case, the challenger was considered weak and received little PAC money.) In other states, we also found a significant fraction of contributions at the cap, though this is for individual and PAC contributions taken together. Our empirical results below are for states, and they suggest that caps do in fact have the effect we hypothesize.

${ }^{5}$ Note that this effect is derived independently of whether a cap is set on other lobbies. It may therefore help to explain why some US companies such as Time Warner, General Motors and Monsanto have voluntarily adopted restrictions on political contributions even before any federal law was enacted.
} 
number of lobbies implies an increase in both the total amount of contributions being made and the level of distortionary policies or total government spending that favor SIGs. More importantly, we show that with endogenous lobby formation, contribution caps on individual lobbies may reduce social welfare. We then test the main predictions of the model using data for US states and find, among other things, that the adoption of contribution caps has a positive effect on lobby formation.

Caps can also affect lobby formation when there is interaction between lobbies. One particularly relevant form of interaction in the context of campaign finance reform is that large increases in contributions from alternative sources increases the "price" that a politician can charge a lobby in exchange for policy favors. We capture this effect by modelling diminishing marginal benefits from aggregate contributions to politicians. This generates an additional channel through which lobbies gain from contribution caps: an increase in the marginal benefit of their contribution allows them to obtain the same policy level at a lower contribution.

Our focus on bargaining between the SIG and the politician over the trade of policy favors for campaign contributions is motivated by empirical studies showing that contributions from Political Action Committees have a significant influence on the voting behavior of Congressmen (see, for example, Stratmann [2002]). Although contributions are also motivated by the desire to have the preferred candidate elected, there is considerable evidence that contributions influence how legislators allocate time, how they act in committees, and how they vote on the floor (Hall and Wayman [1990], Stratmann [1998]). ${ }^{6}$

Our theoretical result on a cap inducing formation of new lobbies does not reflect an existing lobby splitting up into more than one lobby to circumvent the cap. This may or may not be optimal for lobbies, but we simply assume that the cost of forming a second group is too high relative to the additional benefit from lobbying that arises from circumventing the cap. We are not asserting that this assumption is likely (or unlikely) to hold. We are making it in the theoretical model in order to focus on a less obvious effect of the cap on the number of lobbies that has the potential to generate truly new lobbies and therefore decrease social welfare. In the empirical work we address the possibility that the increase in the number of lobbies is due to a split-up effect and show that is not the effect we capture. Our results are also not due to any asymmetries between the benefits from caps to already formed versus newly formed lobbies, nor to lobby competition.

Our results have implications for optimal campaign finance reform. While a reform entailing only

\footnotetext{
${ }^{6}$ There is a debate as to whether contributions buy policy favors. Ansolabehere, et al. (2003) point to a number of studies that have found little or no impact of PAC contributions on roll call votes in the U.S. They do suggest that a subset of donors, mainly corporate and industry PACs, behave as if they expected favors in return and may in fact receive a reasonable rate of return on their contributions.
} 
contribution caps may increase the total amount of money that lobbies contribute to candidates, taxing contributions may counteract the effect of caps in increasing lobbies' power. In contrast, a program of matching contributions may only exacerbate the problem. Hence, any campaign finance reform must consider the effects of reforms on the incentive to form lobbies. More generally, endogenous lobby formation in response to political reform can be quite important in determining the outcome of the reform and can potentially lead to an effect that is the opposite of what is suggested by a static analysis of such a reform.

To test the key prediction that a restriction on existing lobbies can actually increase the number of lobbies, we take advantage of the fact that U.S. states that imposed contribution limits did so at different points in time. We construct a measure of the number of state political action committees (PACs) to use as our dependent variable and, using a difference-in-difference approach, estimate that on average the implementation of caps on contributions from PACs increases their number by about $7-8 \%$ relative to other states. Since the probability of adoption of campaign finance laws may depend on the number of lobbies, we re-estimate our regressions using an instrumental variable estimator to address this potential endogeneity problem. We confirm the positive effect of caps on the number of PACs and find that the result is in fact strengthened considerably. However, we fail to reject exogeneity and thus place greater confidence in the more conservative estimates.

We also find that the effect of caps on PACs is not linear. A cap that is too stringent lowers the number of PACs, but a cap above a certain threshold increases it, both effects are exactly as predicted by the model. The critical threshold is fairly low, with the caps for many of the U.S. states lying significantly above it. Our estimates also indicate that prohibitions on contribution from corporations and unions that do not take place through PACs increase the number of PACs. This is consistent with the prediction from the extended version of the model with lobby interaction. Throughout the estimation we control for state and time fixed effects as well as for other basic state determinants of PAC formation, including population, income, and government revenue. We also account for two important parameters in the model - lobby bargaining power in a state; and the share of informed voters. The findings here are also consistent with the model: an increase in lobby bargaining power is positively correlated with the number of PACs created, as is a decrease in the share of informed voters. This latter information effect on the number of lobbies is another novel finding of the paper.

There is an increasing amount of theoretical work on the welfare implications of campaign finance reform. Prat (2002) and Coate $(2003,2004)$ consider models in which contributions finance advertising and perhaps policy favors as well. Contribution limits may either raise or lower social welfare 
depending on a number of model characteristics, including the nature of advertising (directly versus indirectly informative). In contrast to our paper, the existing theory assumes that the number of interest groups does not change once campaign finance reform is implemented, so that the phenomenon central to our welfare results plays no role. (We discuss this approach further in the concluding section of the paper.) Che and Gale (1998) also take the number of lobbies as fixed and provide a theoretical argument why contribution caps on individual lobby contributions will lead to higher aggregate contributions. Their result depends on a lobby competition effect. ${ }^{7}$ We argue that reforms, and in particular contribution caps, can fundamentally change the bargaining relationship between lobbies and politicians even without lobby competition. This leads to formation of new lobbies, which can overturn some of the conventional wisdom on the effects of caps. In Riezman and Wilson (1997) the number of lobbies may change in response to contribution limits, which may lower social welfare when there are asymmetries between two politicians seeking election or their supporters. A key difference is that in their model contributions and government policies are not determined by bargaining between lobbies and the government. Hence, our key effect that caps may strengthen the bargaining position of existing (symmetric) lobbies and thus induce lobby formation does not arise.

Empirical work on lobby formation, on the other hand, has largely ignored the effect of campaign finance reform. The focus has been on examining the industry characteristics that determine whether an industry has PACs and how much each contributes. Such variables include industry size, concentration and whether it faces government regulations on its economic activities. (Pittman [1988], Zardkoohi [1988], Grier, Munger, Roberts [1994]). Hart (2001) uses firm level data and finds that the probability of a large high-tech firm forming a PAC is higher if it has larger sales, is subject to government regulations on its economic activities and varies with the regional location of the corporate headquarters.

The paper is organized as follows. In the next section, we describe the basic setup. In section 3 we derive the effect of caps on the number of lobbies, taxes and social welfare, and in section 4 we derive the effect of caps when the model is extended to allow for lobby interaction. We analyze complementary reforms that avoid the lobby formation effect of caps in section 5 . In section 6 we provide empirical evidence of the positive effect of campaign finance reforms in US states on PAC formation. The final section contains a discussion and summary of the implications of the main results.

\footnotetext{
${ }^{7}$ They model an all pay auction with two buyers (interpreted as lobbies) bid for the same "object" sold by the government (e.g. a contract). A cap makes the lobby with higher valuation (weakly) less likely to win and increases the surplus from the sale, i.e. aggregate contributions.
} 


\section{Model}

The underlying framework is similar to Grossman and Helpman (1994) with some key differences that we will point out. We consider a small open economy in which individuals are identical except, possibly, for different endowments of non-labor factors. We represent utility as:

$$
U \equiv x_{n}+\sum_{i=1}^{H} u\left(x_{i}\right)
$$

where the subutility functions, $u$, are twice continuously differentiable and strictly concave. The term $x_{n}$, represents the consumption of the numeraire good, $n$, which is produced using only labor with a marginal product of unity. This, along with the assumption of a fixed world price of $n$ at unity and a sufficiently large labor force, implies the wage is unity. We assume symmetry across the non-numeraire goods and thus denote their common exogenous world price by $p$. For given prices an individual who owns the specific factor $i$ has income $E_{i}$ and chooses consumption to maximize utility subject to a budget constraint, $x_{n}+\sum_{i} p x_{i} \leq E_{i}$. Given the assumptions on the subutility, the budget constraint is satisfied with equality and individuals demand $d(p)=u^{\prime}(p)^{-1}$ of each of the nonnumeraire goods, identical for all goods in the absence of consumption taxes or tariffs. An individual's indirect utility is simply the sum of income, $E_{i}$, and consumer surplus, $s(\mathbf{p})=\sum_{i}[u(d(p))-p d(p)]$.

Production of the non-numeraire goods requires labor and a specific factor to be combined according to a constant returns technology. Since the wage is unity the return to the specific factor depends only on the supplier price of the good, $p_{i}^{s}$. The reward to the specific factor is given by the quasi-rent $\pi\left(p_{i}^{s}\right)$ and equilibrium output is $\pi^{\prime}\left(p_{i}^{s}\right)$, where again for simplicity we assume symmetry across sectors in this case in the production function. In the absence of production or trade taxes the producer and world prices are identical.

To redistribute income to lobbies representing capital owners in sector $i$ the government uses (for concreteness) a unit production subsidy, $t_{i}{ }^{8}$ Transfers to lobbies are financed by lump-sum taxes charged on the overall population of $N$ individuals. We assume that the government balances its budget every period, so that each period it must raise $\sum_{i \in L} t_{i} \pi^{\prime}\left(p+t_{i}\right),{ }^{9}$ where $L$ is the endogenously determined set of sectors that are organized as lobbies at a given point. For simplicity we assume

\footnotetext{
${ }^{8}$ What policy is used for redistribution is an important and interesting question in itself, but not one we address. Drazen and Limão (2004) show how a production subsidy can arise as the government's optimal redistribution policy in a framework similar to that used here.

${ }^{9}$ In a small open economy the consumer prices are determined by the world price so they are independent of the production subsidy. Production subsidies affect quantities produced and lower individuals' income but this will only result in lower consumption of the numeraire good.
} 
that each of the members within any given lobby own a similar amount of capital and labor. For organized sectors gross welfare is:

$$
W_{i}=l_{i}+\pi\left(p+t_{i}\right)+\alpha_{i} N\left[s(\mathbf{p})-\left(\sum_{i \in L} t_{i} \pi^{\prime}\left(p+t_{i}\right)\right) / N\right] \quad \text { if } i \in L
$$

where $\alpha_{i}$ is the share of the population that are factor owners of capital in sector $i$, which we assume is a negligible part of the overall population. They therefore take the size of the budget, $\sum_{i \in L} t_{i} \pi^{\prime}\left(p+t_{i}\right)$, as given and do not lobby for it to be reduced. This assumption allows us to focus on the interaction between the government and the lobbies in the absence of any lobby competition effects. Thus the lobby maximizes its gross welfare net of its provision of contributions, which is given by:

$$
V_{i} \equiv W_{i}-C_{i}
$$

Social welfare is then represented by:

$$
W \equiv l+\sum_{i} \pi\left(p+t_{i}\right)-\sum_{i \in L} t_{i} \pi^{\prime}\left(p+t_{i}\right)+N s(\mathbf{p})
$$

Contributions are used by politicians to make campaign expenditures in order to attract votes in an electoral framework. Following Baron (1994) and Grossman and Helpman (1996), we assume that there are two types of voters: "informed" and "uninformed". The first are unaffected by campaign advertisements or other expenditures financed by contributions, while the second can be attracted by higher campaign expenditures. All contributions are used for campaign expenditures on impressionable voters. They assume that the fraction of impressionable votes one party gets relative to the other is simply a function of the absolute difference in their campaign expenditures, that is, in the contributions they succeed in raising. As show in appendix A, under some additional assumptions about functional forms, a politician whose objective is to maximize total votes can be represented as having the objective of maximizing a weighted sum of social welfare and contributions:

$$
G \equiv a W+\sum_{i \in L} C_{i}
$$

As in Grossman and Helpman (1996) we therefore take maximization of (5) as representing the behavior of a politician who solicits contributions from SIGs to maximize his electoral prospects.

Of course, alternative modeling of how contributions are used to influence election outcomes won't 
lead to the simple form of (5). ${ }^{10}$ However, as long as neither side has all the bargaining power, the basic positive results we derive below-that contribution caps that are not too stringent will make lobbies better off and thus give new lobbies the incentive to form-are more general than the specific rationale in the previous paragraph for politicians to desire trading transfers for contributions. On the other hand, the welfare implications of caps, for example, may depend crucially on exactly what functions campaign expenditures serve.

The twin assumptions of additive separability of contributions in $G$ and concentrated factor ownership $\left(\alpha_{i} \rightarrow 0\right)$ imply that there is no economic interaction among lobbies. In many instances interest groups lobby for policies such as production subsidies in their own sector so modelling away motives for lobby competition is not only theoretically useful but also a plausible representation. We introduce a form of lobby interaction below, but for now we restrict our attention to the bargaining between a politician/government and each individual lobby separately. The lobby will offer a contribution in exchange for a production subsidy and the interaction with the politician takes the form of Nash bargaining, as in Drazen and Limão (2004). This type of interaction differs from the menu-auction approach in Grossman and Helpman (1994) where lobbies simply make the government a take-it-or-leave-it offer. Allowing for Nash bargaining leads to key differences in the results, as will be clear below.

\section{Contribution Caps and Lobby Formation}

To derive the effect of contribution caps on the formation of lobbies, we solve the model backwards. First we show the effect of caps on the net welfare for a given lobby. We then model an initial stage of lobby formation and show how contribution caps can induce new lobbies to form by increasing the net welfare of a lobby. Given the symmetry assumptions we made, once a lobby is formed it behaves identically to all others so that, in the second stage, we can focus on a "representative" lobby.

\subsection{Unconstrained Political Equilibrium}

In the absence of contribution caps the political equilibrium in the second stage after lobbies have formed is a pair $(C, t)$ that is efficient, and divides the maximized joint surplus to the politician and lobby according to the bargaining power of the lobby, $\lambda$. Since contributions enter linearly in both the politician's and the lobby's objective they are used to divide the surplus, whereas the production

\footnotetext{
${ }^{10}$ In Coate (2004), for example, contributions finance informative messages that a candidate is qualified.
} 
subsidy is set to achieve a politically efficient outcome. The solution is illustrated in Figure 1, where the vertical line at $t=t^{*}$ represents the contract curve defined by the following condition:

$$
\frac{G_{t}}{G_{C}}=\frac{V_{t}}{V_{C}}
$$

where subscripts represent partial derivatives. This condition reduces to

$$
\frac{t^{*} \pi^{\prime \prime}\left(p+t^{*}\right)}{\pi^{\prime}\left(p+t^{*}\right)}=\frac{1}{a}
$$

The equilibrium contribution level, $C^{*}$, is then set to divide the surplus such that the utility levels obtained by maximizing the Nash product subject to the Pareto frontier are satisfied:

$$
\begin{aligned}
& \operatorname{Max}_{G \geq g^{0}, V \geq v^{0}} U=\left(G-g^{0}\right)^{1-\lambda}\left(V-v^{0}\right)^{\lambda} \\
& \text { s.t. } V=v^{m}-\left(G-g^{0}\right)
\end{aligned}
$$

where $v^{m}$ is the maximum utility for the lobby when the politician is maintained at his reservation utility, $g^{0}$, the level of utility when both $t$ and $C$ are zero (or are combined in a way that provides equal utility). Given the linear Pareto frontier we have the following solution for the utility levels $G^{*}$ and $V^{*}$ of the unconstrained political equilibrium:

$$
\begin{aligned}
G^{*}-g^{0} & =(1-\lambda)\left(g^{m}-g^{0}\right) \\
V^{*}-v^{0} & =\lambda\left(v^{m}-v^{0}\right)
\end{aligned}
$$

where we note that $g^{m}-g^{0}=v^{m}-v^{0}$ because both politician and lobby value contributions identically and, given $t^{*}$, contributions are the only variable that determines the utility level. Point $N$ in Figure 2 represents the Nash bargaining equilibrium in the absence of caps, implying an equilibrium contribution level $C^{*}$.

\subsection{Contribution Caps}

We can now consider the effect of an exogenously imposed cap to show that they can increase the net welfare of existing lobbies.

Proposition 1 :(Effect of caps on lobby payoffs)

$i$. There exists a set of binding contribution caps, $\overline{\mathbf{C}_{i}} \subset\left(0, C^{*}\right)$, that strictly increase lobby $i$ 's net 
welfare iff its bargaining power $\lambda_{i} \in(0,1)$.

ii. If lobby $i$ has all (none) of the bargaining power, $\lambda_{i}=1(0)$, then any binding contribution cap strictly (weakly) decreases its net welfare.

iii. There exist sufficiently low binding caps that strictly decrease the net welfare for a lobby $i$ with $\lambda_{i} \in(0,1]$ (weakly if $\left.\lambda_{i}=0\right)$

iv. Any lobby $i$ with $\lambda_{i} \in[0,1]$ is indifferent between any cap on other lobbies $\overline{C_{j}} \in[0, \infty)$ for $j \neq i$.

Proof: See Appendix B

The first part of the proposition captures a direct bargaining effect: the cap improves the lobby's bargaining position by allowing it to credibly offer a smaller contribution for any given subsidy. The result is illustrated in Figure 1 where $N^{c}$ represents the constrained equilibrium and $V^{c}>V^{*}$ is the lobby's utility. The contract curve is identical to the original one as contributions are increased up to $\bar{C}$. Any further transfer of utility from the lobby to the government can only come through lower subsidies so the contract curve becomes the horizontal segment through $N^{c}$ and $g^{m c}$. We can also see that the maximum government utility is now lower but if the cap is above $C_{0}$ the lobby can still attain $v^{m}$. Using this information we represent the bargaining solution in Figure 2 by $N^{c}$. For contributions below $\bar{C}$ the new Pareto frontier is identical to the unconstrained one, which is represented by the dashed line. When the subsidy level is reduced below the politically efficient level of $t^{*}$ the joint bargaining surplus falls so the new Pareto frontier falls below the original one. Moreover, it is simple to show that the slopes of the two frontiers are identical at the last point where they coincide, $\bar{C}$ and $t^{*}$, therefore the new frontier is steeper and strictly concave. The increase in the steepness of the Pareto frontier implies that it is more costly to obtain increases in government utility for a given reduction in lobby utility, so since the bargaining solution for a given Pareto frontier, is itself efficient it will feature higher utility for the lobby. It is simple to show (as we do in the appendix) that for some caps the improvement in bargaining position for the lobby more than offsets the decrease in overall bargaining surplus from the cap.

The effect on the lobby's net welfare is reversed if it has all the bargaining power $(\lambda=1)$, as part (ii) points out. In that case the lobby appropriates all the bargaining surplus and any constraint such as a cap reduces that surplus and leaves the lobby worse off. This special case is important because it forms the basis for the political equilibrium in the work of Grossman and Helpman, and papers that follow them, whose underlying model structure we share. Conversely, if the lobbies have no bargaining power $(\lambda=0)$, as assumed by Coate (2004), then caps have no effect on their utility. 
Therefore the Nash bargaining solution with intermediate bargaining power generates very different results that could not possibly be predicted by considering either of the extremes.

The third part of the proposition notes that for a sufficiently low cap all lobbies will be worse off, (only weakly so if they have no bargaining power). This is obvious if a cap is set to zero since then the lobby is prevented from bargaining and obtaining any surplus. Therefore it is also true for some positive cap. As the cap is raised it eventually reaches a level $\underline{C}$ at which a lobby is indifferent relative to the unconstrained case. There exist caps between $\underline{C}$ and $C^{*}$ that leave the lobby with higher net welfare than under no caps.

Given the additive separability of contributions in $G$ and the concentration of factor ownership, each lobby is indifferent to caps on other lobbies. This along with part (i) of the proposition imply a basic corollary: all lobbies with intermediate bargaining power benefit from an overall binding cap on contributions, provided it is not too low. Note that this is true even in the absence of lobby interaction/competition effects that may lead to too much lobbying from each lobby's perspective. Note also that with $\alpha_{i} \rightarrow 0$, the net utility of unorganized sectors (which is equal to their gross utility $W_{i}$ ) is independent of the existence of contribution caps and of the number of sectors that do organize.

With a fixed number of symmetric lobbies, $n^{*}$, and no lobby interaction (so that each lobby would contribute $C^{*}$ in the absence of a cap), an enforceable binding cap on the contributions of each lobby lowers the total amount of contributions by $\left(C^{*}-\bar{C}\right) n^{*}$. The equilibrium subsidy rate falls, as is clear from the solution $N^{c}$ in Figure 1 and therefore the total level of taxes required to fund those subsidies also falls. Therefore a cap has the expected effects when the number of lobbies is given-there is less money in politics, fewer distortions and higher social welfare.

Notice also that politicians who value contributions are never better off under a cap. This occurs both because the overall gains from political bargaining fall, represented by the inward shift of the Pareto frontier in Figure 2, and the politician's bargaining position worsens, as represented by the steeper frontier. Therefore no politician supports a cap unless he does not value contributions or has no bargaining power, in which case he is indifferent.

We now turn to endogenous lobby formation to show how the improvement in a lobby's net welfare due to contribution caps leads to new lobbies forming, and under what conditions this leads to larger total contributions, higher taxes to fund production subsidies and lower social welfare. 


\subsection{Lobby Formation}

Consider now the first stage of the political process, namely the decision of groups on whether to form lobbies. Lobbies form if the return to being organized in the second stage, which we have just analyzed, exceeds the cost of lobby formation. We begin with the cost of forming a lobby. Following Mitra (1999) we assume that specific factor owners in any of the $H$ sectors may potentially form a lobby, where the fixed cost (in terms of labor) of forming a lobby in sector $i$ is $F_{i}$. This cost is assumed to differ across sectors because the set of owners for different factors that will potentially organize may differ in their geographical concentration, their organizational ability, or other reasons. For simplicity, this cost of formation will be the only difference across potential lobbies. Denoting by $V^{u}$ the net welfare of an unorganized sector, a sector $i$ will organize as a lobby if

$$
V(\cdot)-V^{u}(\cdot) \geq F_{i}
$$

where under our symmetry assumptions, the left-hand side is identical for all $i$. Note further that, in the above set-up, $\alpha_{i} \rightarrow 0$ implies that both $V$ and $V^{u}$ are independent of $n$, the number of sectors that have organized as lobbies.

Suppose we relabel the sectors that can potentially form, $i=1, \ldots, H$, to reflect their fixed costs in ascending order, so that sector $H$ now denotes the sector with the highest fixed organization cost.

$$
F_{1}<\cdots<F_{n^{*}}<\cdots<F_{H}
$$

so that sectors 1 to $n^{*}$ form lobbies when there are no contribution caps and sectors $n^{*}+1$ to $H$ do not. The marginal lobby $n^{*}$ is determined by the largest $F_{i}$ such that (12) holds.

For simplicity, assume now a continuum of sectors that can organize as lobbies so that ordering the sectors as in (13) implies that $F_{i}$ is continuous in $i$ as well. ${ }^{11}$ We may then represent the fixed cost of formation through a function $F(n)$ where the ordering convention in (13) implies that $F^{\prime}(n)>0$. In this case the equilibrium number of lobbies is determined by an analogue to (12), namely:

$$
V(\cdot)-V^{u}(\cdot)=F\left(n^{*}\right)
$$

where, to repeat, the left-hand side of (14) is independent of $n$ when $\alpha_{i} \rightarrow 0$. Hence, $F^{\prime}(n)>0$

\footnotetext{
${ }^{11}$ The basic result of a positive relation between $n$ and $V$ does not depend on this assumption and would hold as well if the $F_{i}$ only took on a finite number of discrete values.
} 
implies that there is a unique solution to (14). We assume that once a group incurs the fixed cost it can enforce the collection of contributions from each of its members perfectly. In this case it is simple to show that the expected Nash equilibrium of the game played by the members within each group in deciding whether to pay their share of the fixed cost leads to the formation of lobbies up to the point where (14) is satisfied. ${ }^{12}$

The effect of caps on equilibrium lobby formation follows immediately and intuitively. A binding contribution cap that is not too stringent raises $V$, provided $\lambda \in(0,1)$ as shown in proposition 1 , while leaving $V^{u}$ unchanged. Therefore the equilibrium number of lobbies is higher under a cap. Note that when $\lambda=0$ the equilibrium number of lobbies is identical with or without the cap and when $\lambda=1$ the equilibrium number is lower. ${ }^{13}$

The following proposition summarizes the effects of caps on the number of lobbies and the subsequent effects on contributions, subsidies and social welfare, where $\varepsilon_{n \kappa}$ represents the elasticity of the number of lobbies with respect to a marginal tightening of the cap at $C^{*}$. Similarly for $\varepsilon_{T \kappa}$ which refers to the elasticity of the value of the production subsidy per existing lobby.

Proposition 2 : (Contribution caps, lobby formation and social welfare)

When $\lambda=\lambda_{i} \in(0,1)$ for all $i$ then the set of binding contribution caps, $\overline{\mathbf{C}}_{i} \subset\left(0, C^{*}\right)$, that strictly increase the net welfare $V$ of all $n^{*}$ operating lobbies with $\lambda_{i}$ will:

$i$. Lead to the formation of new lobbies with $F>F\left(n^{*}\right)$

ii. Increase total contributions iff $\varepsilon_{n \kappa}>1$

iii. Increase total production subsidies and taxes iff $\varepsilon_{n \kappa}>-\varepsilon_{T \kappa}$

iv. Reduce social welfare iff $\left(-\left(\pi\left(p+t^{*}\right)-\pi(p)-t^{*} \pi^{\prime}\right)\right) \varepsilon_{n \kappa}>-\left(t^{* 2} \pi^{\prime \prime} /\left(1+t^{*} \pi^{\prime \prime} / \pi^{\prime}\right)\right) \varepsilon_{T \kappa}$

Conditions ii, iii and iv are satisfied if either $F^{\prime}\left(n^{*}\right)$ is sufficiently low or $F(0)$ is sufficiently high.

Proof: See Appendix B

Part (i) of the proposition simply summarizes the lobby formation effect already described. Part (ii) reflects the opposing effects of the cap on total contributions. Caps decrease individual contributions from existing lobbies, naturally the elasticity for those lobbies is unity, but it increases the

\footnotetext{
${ }^{12}$ When there is more than one factor owner within the sector there is an incentive to free ride and not pay the formation cost that is also a Nash equilibrium to the lobby formation game played by factor owners within a sector. However, as Mitra (1999) argues, such an equilibrium does not survive simple refinements that involve pre-play communication such as Pareto-dominance or coalition proof.

${ }^{13}$ Note however that if $n^{*}$ lobbies were already formed and then an exogenous contribution cap is imposed any existing lobbies would still be operating since we are modelling the formation costs as fixed and sunk, which would imply no change when $\lambda=1$.
} 
number of lobbies that form and contribute, with elasticity $\varepsilon_{n \kappa}$. Since once the lobbies form they are symmetric all that is required is that the elasticity of formation exceed the direct effect, $\varepsilon_{n \kappa}>1$. Part (iii) provides a condition similar to (ii) for total production subsidies, which increase if sufficient new lobbies are formed such that the new subsidies now paid more than offset the decrease in the subsidy paid to the previously existing lobbies. The intuition is clear, if initially there are few organized lobbies then a tightening of the cap and resulting reduction in the subsidy rate will have a small effect on total production subsidies for existing lobbies. If that tightening leads to considerable lobby formation then the new equilibrium level of total production subsidies $\Sigma_{i \in L^{\prime}} t_{i} \pi_{i}^{\prime}$, increases, note that $n$ does not affect the equilibrium subsidy rate, $t$. The condition for taxes follows from the balanced budget constraint.

Part (iv) provides a necessary and sufficient condition for caps to lower social welfare. The left hand side of the condition captures the social cost of subsidies to newly formed lobbies, the expression in parenthesis is positive because the increase in profits is insufficient to cover the subsidy cost. The right side of the condition captures the benefit-a reduction in the distortion arising from a lower production subsidy on the existing lobbies. If total production subsidies increase then it is sufficient for the social loss per new lobby $-\left(\pi\left(p+t^{*}\right)-\pi(p)-t^{*} \pi^{\prime}\right)$ to exceed the gain from the marginal reduction in the distortion caused by the lower subsidy rate for existing lobbies. ${ }^{14,15}$

Notice that lobby formation may also imply that politicians gain from caps and therefore may support them. If total contributions increase and the politician places relatively little value on social welfare then he will be better off with the cap.

\section{Diminishing Returns to Aggregate Contributions and Lobby Com- petition}

In the baseline case we modeled away all lobby interaction. One interaction that may be important is that the marginal benefit of any given contribution by a lobby depends on how much a politician collects from other lobbies. If he collects a lot, the marginal benefit of any given contribution may be low, so that each individual lobby will not be able to extract much from the politician in the form of policy concessions. We represent this by modifying the government objective so that total

\footnotetext{
${ }^{14}$ To see this clearly we can also write $-\varepsilon_{T \kappa} t^{* 2} \pi^{\prime \prime} /\left(1+t^{*} \pi^{\prime \prime} / \pi^{\prime}\right)=-\varepsilon_{t \kappa} t^{* 2} \pi^{\prime \prime}$ where $\varepsilon_{t \kappa}$ represents the elasticity of the subsidy rate.

${ }^{15}$ Although the results in Proposition 2 are easiest to see when all lobbies have the same bargaining power $\lambda$, they do not depend on this. As long as no lobby has a $\lambda$ of either 0 or 1 , a contribution cap would make all lobby types better off and therefore lead to new lobby formation. The exact conditions, analogous to those in proposition 2 , under which this would increase total contributions, subsidies and lower welfare would differ.
} 
contributions are evaluated according to an increasing, concave function $\Psi$ :

$$
\hat{G} \equiv a W+\Psi\left(\sum_{i \in L} C_{i}\right)
$$

Since all lobbies make identical contributions, we may write the contributions term as $\Psi(n C)$. If we retain the assumption that each lobby $i$ bargains with the government only over the policy in its sector $t_{i}$-which is reasonable if no lobby is too large-then it is simple to derive the additional effect of the contribution caps on the number of lobbies. In this case no individual lobby $i$ has an incentive to offer contributions to the government to affect policies in other sectors.

We assume first that the contribution of any single individual lobby $i$ is too small to change the marginal benefit of aggregate contributions, that is, $\Psi^{\prime}\left((n-1) C+C_{i}\right) \approx \Psi^{\prime}((n-1) C)$, for any $C_{i}$ that a politician can extract from a lobby and still maintain the lobby at the reservation utility level $v^{0}$. However, we further assume that there is a sufficiently large number of lobbies such that when a binding cap $\bar{C}<C$ is set it increases the marginal benefit of aggregate contributions, that is, $\Psi^{\prime}\left((n-1) \bar{C}+C_{i}\right)>\Psi^{\prime}\left((n-1) C+C_{i}\right)$. The first assumption implies that the analysis of the direct effect of a cap on lobby $i$ remains identical to parts i,ii and iii of proposition 1 . The key difference is therefore that a cap on other lobbies will now benefit lobby $i$ by raising the marginal benefit of its contributions.

In order to concentrate on the indirect effect on lobby $i$ we consider the case where all other lobbies face a binding contribution cap, but lobby $i$ 's contributions are unrestricted. Since sector $i$ lobbies only for $t_{i}$ and its contributions do not change the marginal benefit of aggregate contributions, the equilibrium $t_{i}$ is still defined as the solution to equation (6), which is now given by

$$
\frac{\hat{t}_{i} \pi^{\prime \prime}\left(p+\hat{t}_{i}\right)}{\pi^{\prime}\left(p+\hat{t}_{i}\right)}=\frac{\Psi^{\prime}\left((n-1) \hat{C}+\hat{C}_{i}\right)}{a}
$$

Given our assumption that $\Psi^{\prime}\left((n-1) C+C_{i}\right) \approx \Psi^{\prime}((n-1) C), \hat{t}_{i}$ is independent of the equilibrium $\hat{C}_{i}$ for any politically feasible level of contributions. In order to compare the effect of a cap in this setup with the original one, we could normalize $\Psi$ so that $\Psi^{\prime}\left((n-1) \hat{C}+\hat{C}_{i}\right)=1$, implying that in the absence of a cap, $\hat{t}_{i}=t^{*}$. The effect on $t_{i}$ of a cap $\bar{C}<\hat{C}$ on contributions from other lobbies is then exactly equivalent to a reduction in the politician's weight on social welfare, $a$. This follows immediately from $(16)$ since $\Psi^{\prime}\left((n-1) \bar{C}+\hat{C}_{i}\right)>\Psi^{\prime}\left((n-1) \hat{C}+\hat{C}_{i}\right)$. The equilibrium production subsidy for $i$ therefore increases with a cap on other lobbies.

The indirect effect of a cap on other lobbies on lobby $i$ 's utility is easy to derive. Given $\hat{t}_{i}$ from 
(16) the equilibrium transfer is determined as before by maximizing the Nash product in (8). With no cap on $i$, the slope of the Pareto frontier is linear, but with slope $-1 / \Psi^{\prime}((n-1) \bar{C})>-1 / \Psi^{\prime}((n-1) \hat{C})$ (=-1 under the normalization above). With a linear Pareto frontier lobby $i$ 's equilibrium utility is given by (11). When $\alpha_{i} \rightarrow 0$, the reservation value $v^{0}$ remains unchanged, while $v^{m}$ increases because the cap on other lobbies increases the marginal benefit of $i$ 's contributions, so that it needs to make a lower contribution to maintain the government indifferent relative to its reservation value. Hence, the cap on other lobbies raises lobby $i$ 's utility when there are diminishing returns to aggregate contributions.

The argument above also holds exactly for the marginal unorganized lobby and therefore provides another channel by which caps increase the number of lobbies. Note that in deriving the indirect effect we did not impose any limits on the cap. In fact the lower the cap is the stronger the positive effect on $i$ 's utility. This contrasts with the direct effect derived in proposition 1 where the direct effect of sufficiently low caps is to lower lobby utility. Moreover, this indirect effect of caps in increasing the marginal benefit of individual contributions can apply to caps on any source of contributions that enter the aggregate contributions functions. This is a result that we will explore in our empirical work.

\section{$5 \quad$ Alternative Reforms}

The conclusions of Proposition 2 imply that contribution caps, presumably meant to reduce the influence of special interests in the political process, may have just the opposite effect. Caps may increase the number of organized lobbies, total contributions and subsidies to special interests. Moreover caps may reduce social welfare. In section 6 below we present empirical evidence that caps do in fact foster lobby formation, so the negative effects of caps are a real possibility. One response to these findings is to argue that limitations on contributions should be eliminated. We would argue instead that it may be necessary to link contribution limitations to other forms of campaign or electoral reform in order to come closer to achieving their desired purposes. In this section we explore two possibilities in the context of this model.

The basic question we address is the following. Since a ban on political contribution is unlikely to be politically feasible, are there simple reforms that are alternative or complementary to positive contribution caps that might ensure that individual and total contributions as well as subsidies do not rise and that social welfare does not fall? 


\subsection{Taxing Contributions}

Consider first a tax on contributions to eliminate the incentives for lobby formation due to a cap. Denote the tax rate on contributions by $\mu\left(C_{i}\right)$ and assume that the net revenue collected is redistributed lump-sum to the population. With enforcement or collection costs of $\beta \in[0,1]$ per unit then $(1-\beta) \mu\left(C_{i}\right) C_{i}$ is available for redistribution from each $C_{i}$ taxed. The government objective may now be written as:

$$
\begin{aligned}
G & \equiv a\left(l+\sum_{i} \pi\left(p+t_{i}\right)-\sum_{i \in L} t_{i} \pi^{\prime}+\sum_{i \in L}(1-\beta) \mu\left(C_{i}\right) C_{i}+N s(\mathbf{p})\right) \\
& +\sum_{i \in L} C_{i}\left(1-\mu\left(C_{i}\right)\right) \\
& \equiv a\left(l+\sum_{i} \pi\left(p+t_{i}\right)-\sum_{i \in L} t_{i} \pi^{\prime}+N s(\mathbf{p})\right)+\sum_{i \in L}\left(1-(1-a(1-\beta)) \mu\left(C_{i}\right)\right) C_{i}
\end{aligned}
$$

From this we immediately see that the marginal benefit of contributions falls only if the government places sufficiently low weight on social welfare. For example if $\beta=0$ there are no enforcement costs and the tax rate is constant, the marginal benefit of contributions is $1-(1-a) \mu$, which is lower than the marginal benefit in the absence of a tax (i.e., 1) only if $a<1$, that is, only if the government places less weight on social welfare than contributions. With $\beta>0$ the condition is $a<1 /(1-\beta)$.

Assume for now that this is the case, that is, $a<1$, which also implies $a<1 /(1-\beta)$. Consider the following schedule for taxing contributions

$$
\mu\left(C_{i}, \bar{\mu}\right)=\left\{\begin{array}{cl}
\bar{\mu} & \text { if } C_{i} \leq \bar{C}_{i} \\
\frac{1}{1-a(1-\beta)} & \text { otherwise }
\end{array}\right.
$$

That is, up to some contribution level $\bar{C}_{i}$ there is a constant tax rate $\bar{\mu} \geq 0$; beyond that contribution level the tax rate is sufficiently high that the marginal benefit of contributions to the politician is zero, so that the rate after $\bar{C}_{i}$ is effectively a cap since the politician will not accept individual contributions above $\bar{C}_{i}$ to increase production subsidies. Hence, $\bar{\mu}=0$ is the case of propositions 1 and 2 . We now show that with a tax system with $\bar{\mu}>0$, the gains in lobby utility from the cap can be offset, so that no additional lobbies form. Denote by $C^{\mu} \equiv C(\mu(C), \bar{C})$ the equilibrium contribution under the tax system (18), $n^{\mu}$ the equilibrium number of lobbies under (18), and $t^{\mu}$ the equilibrium production subsidy under (18).

\section{Proposition 3 : (tax on contributions)}

When the politician values contributions more than social welfare there exists a reform composed of a tax on contributions $\mu\left(C_{i}\right)$ with $\bar{\mu} \in\left[0, \frac{1}{1-a(1-\beta)}\right)$ for any $\bar{C} \in\left[0, C^{*}\right]$ such that 
i. $V(\mu(C), \bar{C}) \leq V^{*}$ and $V^{u}(\mu(C), \bar{C})=V^{u *}$ (where $V^{u}$ is the welfare of unorganized lobbies) so that no new lobbies form;

ii. $C^{\mu} \leq C^{*}$ and $n^{\mu} C^{\mu} \leq n^{*} C^{*}$;

iii. $t^{\mu} \leq t^{*}$ and $\sum_{i \in L} t_{i}^{\mu} \pi^{\prime}\left(p+t_{i}^{\mu}\right) \leq \sum_{i \in L} t_{i}^{*} \pi^{\prime}\left(p+t_{i}^{*}\right)$;

$i v$. Social welfare is the same or higher than under no reform.

Proof: See Appendix B

In short, taxing contributions can address the potential negative effects of a simple cap on contribution caps.

\subsection{Matching Contributions}

Another reform that is used in U.S. Presidential campaigns and has been proposed elsewhere is the use of public funds to match private contributions. Since government matching of some fraction of contributions can be seen as a negative tax, Proposition 3 also illustrates the potential problems of matching private contributions with public funds. Matching at some rate can be easily modelled in our framework by having $\mu<0$ in (17a). Effectively the matching funds work as a subsidy that increases the marginal benefit of private contributions provided that $a<1$, which implies $a(1-\beta)<1$. So, according to Proposition 3, one would expect that using matching contributions as a complementary reform would actually exacerbate the potentially negative effects of contribution caps. At a given cap allowing for $\bar{\mu}<0$ will increase subsidy rates and lobby welfare thus leading to the creation of additional lobbies. The larger subsidy rate, number of lobbies and the cost of the matching funds will lower social welfare at a given cap. ${ }^{16}$

Naturally, when $a<1$, matching funds leave the politician better off by giving him a "technology" to transform tax revenue into contributions that are more highly valued. Thus this scheme rewards politicians that adopt caps. However, by tying the incentive to existing contribution levels it introduces additional distortions. A better way to induce the adoption of caps by politicians could be to provide public funding that is independent of contributions.

\footnotetext{
${ }^{16}$ This discussion also points to another interesting conclusion. If the government values social welfare sufficiently, i.e. if $a(1-\beta)>1$ then matching funds may help to achieve some of the same goals as a tax when $a<1$. Note that when $a(1-\beta)>1$ an increase in the subsidy rate actually decreases the marginal benefit of contributions. The reason is simple: the government now values social welfare sufficiently that it looses from raising tax revenue and "transforming" it into matching contributions. However, if the matching scheme is a voluntary one, the politician would not choose to do this. Another difference relative to the tax scheme is that even if $a(1-\beta)>1$ the subsidy would be costly to the public so it is not clear that social welfare would rise.
} 


\section{Caps and Lobby Formation: Evidence from Reforms in US States}

\subsection{Predictions}

Using the definitions of $V($.$) and V^{u}($.$) to rewrite (14), we may write the equilibrium number of$ lobbies in terms of the exogenous variables in the model

$$
\begin{aligned}
F(n) & =\pi\left(p+t_{i}(\bar{C}, a)\right)-C_{i}(\lambda, \bar{C}, a, p)-\pi(p) \\
n & =f(\bar{C}, \lambda, a, c, p)
\end{aligned}
$$

We believe that the effects of caps on the number of lobbies applies in settings broader than our specific model. Therefore we do not limit ourselves to a structural estimation focused on industry related lobbies. Instead we use a broader measure of lobbies-political action committees (PACs)-to test the main predictions of interest from the model:

1. The number of PACs depends on the existence of a limit on PAC contributions.

2. When lobbies have some but not all bargaining power then a cap, $\bar{C}$, on all PACs increases $n$ if that cap is not too low and decreases it otherwise.

3. In the presence of diminishing marginal benefits to aggregate contributions a cap on contributions from sources other than PACs, e.g. corporations or unions, increases the number of PACs. Note that, unlike the effect of caps on PACs, a cap on other sources has a positive effect on the number of PACs independently of how stringent it is.

Three secondary predictions arise directly from this model which should also arise in a more general model. First, when lobbies have higher bargaining power they are more likely to form because contributions for a given subsidy are lower and thus the gain to organizing higher. Second, increases in the share of informed voters, $a$, leads the government to place more weight on their welfare and in equilibrium this lowers lobby utility. So increases in $a$ lower lobby formation. In our model that occurs because increases in $a$ imply a lower subsidy rate, as is clear from (7). Third, increases in the fixed cost of lobby formation lead to lower lobby formation.

\subsection{Empirical Approach and Data}

The basic estimating equation is:

$$
\ln n_{i t}=\beta 1\left(\bar{C}_{i t}\right)+\mathbf{X}_{i t} \boldsymbol{\gamma}+\mu_{i}+v_{t}+u_{i t}
$$


where $\ln n$ is the log number of PACs in state $i$ in election cycle $t$ and $1\left(\bar{C}_{i t}\right)$ is an indicator of whether or not a state regulates contributions by PACs. We include time and state effects, respectively $v_{t}$ and $\mu_{i}$, as well as a number of time-varying state variables in the vector $\mathbf{X}_{i t}$, where we discuss below how these relate to the theoretical model. Our data range from 1986 to 2000. Since our unit of observation is an election cycle, we have eight observations per state.

Data on PAC state campaign finance legislation were obtained from the biannual publication Campaign Finance Law, from the Federal Election Commission. We classified a state as having no restrictions when the state allowed unlimited PAC giving to candidates for state offices $\left(1\left(\bar{C}_{i t}\right)=0\right)$ and having restrictions otherwise $\left(1\left(\bar{C}_{i t}\right)=1\right)$. To interpret $\beta$ we can take the time difference of a state that implements a law and then subtract the difference of a state that did not. Then, conditional on the same $\mathbf{X}_{i t}$, we can interpret $\beta$ simply as the one time effect on the number of lobbies in that state from implementing a campaign finance law. So our basic approach to identify $\beta$ is to use the within variation available through the nineteen US states that have implemented campaign finance reform laws between 1986 and 2000 relative to the 31 states did not implement any in this period. ${ }^{17}$

For the period 1986 to 2000, data on the number of PACs that contributed to state candidates are not systematically available. ${ }^{18}$ Therefore we use PACs from the state that contribute to federal candidates as a proxy for PAC formation at the state level. The source is the Federal Election Commission, which defines these PACs as those organizations that contribute to federal campaigns. Each PAC reports their mailing address to the FEC and we define a PAC as being from a particular state by their mailing address. ${ }^{19}$

There is one potential disadvantage and one advantage to using this measure. The disadvantage is that our maintained assumption may not hold, i.e. the number of new lobbies from a given state may not be positively correlated with new lobbies from that state that lobby at the federal level. However, there may be theoretical reasons in either direction. For example, if state and federal policies lobbied for are substitutes then lobbying at the federal and state level may also be substitutes, but we will see the evidence is not consistent with this hypothesis. At the same time it is likely that several policies are not substitutes and that, after incurring the cost of forming and lobbying at the state level, the SIG will find it relatively cheap to lobby also at the federal level, generating a positive correlation

\footnotetext{
${ }^{17}$ The nineteen states are: Arizona, Colorado, Georgia, Idaho, Kentucky, Louisiana, Massachusetts, Maryland, Missouri, Nebraska, New Jersey, Nevada, New York, Ohio, Oregon, Rode Island, South Carolina, Tennessee and Washington.

${ }^{18}$ Data on lobbies registered in each of the 50 states have been collected by Gray and Lowery (1997). However, since we are specifically concerned with the exchange of contributions for favors (rather than more general lobby activities), we analyze PAC formation rather than lobby formation. PACs can contribute to candidates, while lobbies can not.

${ }^{19}$ About $13 \%$ of all PACs have their headquarters in Washington DC and we exclude them from the analysis.
} 
between the series. ${ }^{20}$

A potential advantage of using federal data is that it may address the problem of PACs forming under a different name in response to binding contribution caps in order to evade the cap. In this case, a positive correlation could be observed between the cap and the number of state PACs, even though the cap did not induce formation of any really new PACs. Whether or not this occurs depends on the cost of setting up additional state PACs relative to the benefit of making contributions above the cap. To understand how the use of federal data is likely to minimize this problem consider the following case. PAC $A$ is formed before a state law imposing a cap is passed and it lobbies at the federal and state level. After the state law is passed, the SIG represented by $A$ finds it profitable to create another PAC, $A^{\text {new }}$, to channel contributions above the cap at the state level. Since the cap binds only at the state level this SIG will have no motive to register the new PAC and use it to lobby at the federal level. Hence the federal data are unlikely to be contaminated by the split-up effect.

However, even with federal PACs the concern remains that PACs may decide to split into several PACs when facing a contribution limit for the reason mentioned, thus confounding the empirical results. To analyze whether this is a quantitatively important concern for our estimation, we also collected data on the identity of PAC sponsors from the FEC. Although PACs may split because of caps that is not the case for their sponsors.

Table 1 reports some descriptive statistics. The number of PACs varies greatly from state to state. The mean number of PACs is 72 with a minimum of zero PACs in Vermont in 1996 and over 400 PACs in California. The average number of sponsors in our data set is 66, suggesting that some organizations are sponsoring more than one PAC. About fifty four percent of our state-year observations are subject to a limit on PAC contributions. There have been 36 states with limits on PACs at some point in time. In 2000 this number was 34 since Missouri and Oregon introduced and subsequently removed their limits. The limits range from $\$ 200$ (Oregon in 1996) to $\$ 73,000$ in Nebraska, with a median of $\$ 2,000$. None of the states completely prohibits contributions from PACs.

Three of the variables in the vector $\mathbf{X}$ proxy for important variables in the model: lobby bargaining power in a state, $\lambda$, the cost of lobby formation, $c$, and the share of informed voters, $a$. To capture $\lambda$ we

\footnotetext{
${ }^{20}$ To examine empirically whether federal PACs are a reasonable measure for the presence of state PACs we collected data on state PACs that contributed to candidates in the 2000 election in Arizona, California, Idaho, Indiana, New York, and Missouri. The correlation coefficient between state PACs contributing to state candidates and state PACs contributing to federal candidates is 0.70 and statistically significant at the one percent level, suggesting that our measure is strongly correlated with state PACs. To address the concern that this correlation may simply reflect the fact that larger states have both more state and federal PACs, we estimated a regression of log state PACs on log federal PACs, state per capita income and population size. The point estimate on log federal PACs was 0.4 and statistically significant at the 3 percent level.
} 
construct a measure of state specialization. More specifically we construct an Herfindahl-Hirschman index from the employment in a state collected by the BEA at the three digit level SIC code. If average employment is similar across sectors then an increase in this index captures increased specialization in a set of sectors at the 3-digit SIC level. In the extreme if most workers in a state are employed by a small set of industries then those industries have considerable bargaining power in bargaining with state politicians. Therefore our model predicts this measure to be positively correlated with the number of lobbies in a state.

To proxy for the cost of lobby formation, $c$, we employ a measure of geographic concentration, similar to Trefler (1993). Our measure captures if a given sector is relatively more concentrated in particular states. Greater geographical concentration may reduce the free-rider problem and thus the cost of organizing so if a state has a large share of an industry that is geographically concentrated we posit that PACs are more likely to form in this state. ${ }^{21}$

Our proxy for $a$ is a voter information variable, since the more informed voters are about the political process, the stronger the incentive of the politician to place more weight on the welfare of voters as opposed to contributors. We construct this variable using a recurring question in the biannual National Election Study (NES): "We're interested in this interview in finding out whether people paid much attention to the election campaign this year. Take newspapers for instance-did you read about the campaign in any newspaper?" The response was coded 0 if the answer was "No, read no newspapers about the campaign" and 1 when the response was "Yes, read newspaper(s) about the campaign." Each individual is identified by the residence state and we aggregated the responses to the state level. ${ }^{22}$

The NES does not always have all states in its survey. Of the 400 possible observations points for the 50 states between 1986 and 2000, we were able to obtain 285 observations from the NES. To obtain data for all states we posited a model for the share of informed voters in a state as a general function of per capita income, urbanization rate and education in the state. We then used a second order Taylor approximation and obtained predicted values of the share of informed voters for all states. The predicted value is our voter information measure, which, according to the model, should have a negative effect on the number of PACs. ${ }^{23}$

\footnotetext{
${ }^{21}$ Using employment concentration as a proxy for a lobbies' bargaining power and regional concentration as a measure of fixed cost of formation, makes the most sense for corporate and trade association PACs. Over 66\% of PACs in our sample are classified as corporate or trade PACs by the FEC.

${ }^{22}$ We used linear interpolation for the two years in which the question was not asked $(1994,1998)$.

${ }^{23}$ More specifically we estimated a regression in logs of the share of informed voters on per capita income, urbanization rate, education and education squared, including also the interactions of all these variables and year dummies. Education is measured as the percent of individuals with at least a high school degree.
} 
Tables $1 \mathrm{a}$ and $1 \mathrm{~b}$ provide summary statistics of the variables and Table 6 describes their source and, when applicable, how we calculate them.

\subsection{Estimation}

Table 2a reports OLS estimates of equation (1E). ${ }^{24}$ All the specifications include state and time effects that are not reported. Column 1 shows that a state's enactment of limits on campaign finance laws leads to approximately an 8.4\% increase in the number of PACs in that state. In section 6.5 we estimate that for sufficiently low caps the effect is actually negative as predicted by the model but it becomes positive for high enough caps. The results are not driven by any single state and remain unchanged if we re-estimate dropping one state at a time.

In column 2 we introduce a measure for whether contributions from corporations and/or unions, that are not channeled through PACs, are prohibited by the state. When this is included, we find that limits on PACs increases the number of lobbies in a state by approximately $7.3 \%$, and that the combined effect of limits on PACs, unions and corporations leads to a $14.1 \%$ increase in the number of PACs. This result is consistent with the prediction of the extended version of our model: the reduction in contributions from corporations and unions increases the marginal benefit of contributions from PACs and therefore leads more of them to form. The last two columns are identical to the first two except that they exclude Nebraska. One of our instruments is not defined for that state so we exclude it here also in order to subsequently compare these results with the IV estimation.

Columns 3 and 4 of Table 2a show the effects of contribution caps and the other covariates on the number of PAC sponsors. The results of caps on lobby formation are very similar to the results in the first two columns where the dependent variable was PACs, and the remaining covariates have a similar effect as in the previous specifications. These results suggest that a PAC split-up effect is not a quantitatively important concern. Because we are interested in PAC formation and the impact of contribution caps on the decision to form a PAC, the remaining specifications in this paper will have PACs, not sponsors, as the dependent variable.

Our proxy for industry bargaining power also has a positive effect on the number of lobbies, as predicted by the model. We also use the square of our HHI measure to capture the non-linearity in the effect of the variable on the expected number of lobbies formed. We expect the HHI variable to have a non-linear effect on the expected number of lobbies formed. An increase in specialization makes any given industry more likely to form a lobby. However, as employment becomes concentrated in fewer

\footnotetext{
${ }^{24}$ Although the dependent variable is "count data" OLS is appropriate because the number of PACs is fairly "continuous".
} 
industries there will be fewer lobbies that will potentially form. Thus, we expect that at low levels of specialization (all industries active) an increase in the specialization increases lobby formation. We expect the opposite at high levels, and this is what we find, though the effects are not statistically significant. The marginal effects show the effect is positive but insignificant at the minimum and at the mean level of concentration. The geographic concentration measure has the hypothesized sign: states with higher shares of industries that are more highly regionally concentrated in some part of the country have a larger number of PACs. This variable does not vary much over time, which may explain why it is not statistically significant.

State per capita income is positively and significantly associated with increases in the number of PACs. Given how broad this measure is, any one specific interpretation is suspect. The relationship may be driven by the positive effect of income on an individual's political involvement (e.g. the share of registered voters increases with income). Moreover, increases in income also increase demand for certain government provided goods such as environmental protection, etc., thus increasing the return to lobbying on those issues. State income taxes have no statistically significant effect on lobby formation. State population has a positive but insignificant effect; perhaps because population changes only slowly over time and the effect of state size is already absorbed by our state fixed effects.

The share of informed voters has the predicted negative effect on PAC formation. The point estimates are negative and statistically significant in all specifications, and they can be interpreted as elasticity estimates. They suggest that a one percent increase in the share of politically informed voters leads to an approximately 0.6 percentage point decrease in the number of PACs. To our knowledge this is the first estimate of the effect of voter information on lobby formation.

\subsection{Endogeneity}

Voters may favor caps on contributions if they anticipate an increase in lobby activity due to new lobbies forming. This raises the possibility that the enactment of a campaign finance law in our analysis is endogenous since there may be unobserved variables that change over time that determine both lobby formation and consequently the passage of laws capping contributions. To address this possibility we apply instrumental variables.

Traditionally Democrats have favored limits on PAC contributions and we will use a set of instruments reflecting political control at the state level. We assume that political control by Democrats versus Republicans is a determinant of campaign finance legislation but that it is uncorrelated with lobby formation. One justification to exclude these instruments as regressors from the main equation 
is that we already control for state income taxes and transfers, which are likely to be correlated with political control at the state level. Given that we have more instruments than endogenous variables we can use the resulting over identifying restrictions to test this and do find that the instruments are indeed uncorrelated with the error term in the main equation.

More specifically our instruments reflecting political control are whether the governorship is held by a Democrat and the change relative to the previous election. We also use the share of seats held by Democrats in the state assembly and the change relative to the previous election. Since this relation may be non-linear we also employ the squares of these variables. We also interact the changes in governorship and Democratic seats, which captures if a law is more likely to be enacted when Democrats gain control of both institutions. In addition to the political control variables we also use a measure of how liberal a state's citizen's are and whether it has an initiative process as well as their interaction. We tested our identifying assumptions by performing a test of over identifying restrictions. We can not reject the null hypothesis, lending support to the assumption that our instruments are valid.

The instrumental variable estimates are reported in Table $3 .^{25}$ (The corresponding first stage regressions and test statistics for the significance of the instruments are reported in Table 4.) The results in the first two columns of Table 3 are directly comparable to those in the last two columns of Table $2 \mathrm{a}$ and are qualitatively similar. The coefficient on the finance law remains positive and significant. Most notably the point estimate actually triples relative to the estimates for the same sample in Table 2a suggesting that the growth in the number of PACs from enacting the law is 29\%. We performed a Hausman test for whether the data suggest that campaign finance laws are in fact endogenous in the PAC formation regression. We cannot reject the null hypothesis that the OLS estimates are consistent at the $10 \%$ and $5 \%$ level for the specifications in columns 1 and 2 respectively and at $10 \%$ for the specifications in the last two columns, which we discuss below. Therefore we focus on the more conservative OLS estimates.

\subsection{Quantifying the Effects}

We first compare the importance of the average effect of a change in the contribution law relative to that of other variables. We then augment (1E) to estimate and quantify the marginal effects of the law at different cap values for PAC contributions, since the model predicts these should be negative for low caps and positive for higher ones.

\footnotetext{
${ }^{25}$ The sub sample excludes Nebraska since legislators to the unicameral legislature are non-partisan so some of our instruments for political control are not defined.
} 
It is interesting to compare how important PAC limits are relative to lack of voter information in causing more PACs to form. According to a standard measure that accounts for the standard deviation in the regressors the PAC effect is about 5 times more important. ${ }^{26}$ Alternatively, from the estimates of column 1 in Table $2 \mathrm{a}$ we can see that the effect of the limit in increasing PACs is equivalent to a $12.8 \%$ reduction in voter information. Only $1.5 \%$ of the state-year observations in our sample had reductions this large in voter information over any two year period.

The theoretical model offers other empirical predictions about the effect of caps on the number of lobbies. One that we already referred to is the effect of prohibitions on other sources of contributions. Imposing a prohibition on either corporations or unions increases the number of PACs by approximately $7 \%$; therefore the effect is of the same magnitude as the laws that affect PAC contributions directly so the comparisons in the previous paragraph relative to voter information is similar for this variable.

The model also predicts that sufficiently low contribution caps lower the gain to lobbying, thus reducing the number of lobbies that form. To estimate this effect we use additional information on the value of the cap. The general form of the equation that we now estimate, which allows for non-linear effects, is

$$
\ln n_{i t}=\kappa\left(\bar{C}_{i t}, \boldsymbol{\delta}\right) 1\left(\bar{C}_{i t}\right)+\mathbf{X}_{i t} \boldsymbol{\gamma}+\mu_{i}+v_{t}+u_{i t}
$$

In the first column of Table $2 \mathrm{~b}$ we use $\kappa\left(\bar{C}_{i t}, \boldsymbol{\delta}\right)=\delta_{1}+\delta_{2} \ln \bar{C}_{i t}$. Note that in this specification the interpretation of $\delta_{1}$ is the effect of implementing a cap of $\$ 1$. A cap of $\$ 1$ leads to a $28 \%$ decrease in the number of lobbies, as predicted by the model. The positive coefficient on $\ln \bar{C}_{i t}$ (that is, $\delta_{2}$ ) indicates that conditional on having a cap, an increase in the cap leads to an increase in the number of lobbies. Hence, the negative effect given by $\delta_{1}$ is fully offset if the chosen cap is sufficiently high. According to the estimates in Table $2 \mathrm{~b}$ column 1 if the cap is $\$ 673$ then the campaign finance law has no effect on lobby formation. A law that implements any higher caps is predicted to increase the number of lobbies. The finding that a sufficiently low cap reduces the number of lobbies is not consistent with the hypothesis that federal policies and lobbies are substituting for state lobbies. If that was the case then the strongest effect of a state cap on the number of federal lobbies would occur when that cap is at its lowest.

In Table 5 we list the states with limits. Out of the 36 states that had limits only in 4 is that limit below \$673: Maine, Missouri, Minnesota and Oregon. The 10th percentile for the limit taken

\footnotetext{
${ }^{26}$ This refers to a comparison of the beta effects, which are defined as the product of the coefficient multiplied by the ratio of the standard deviation of the independent and dependent variable (e.g. for the limit the effect is $0.84 * 0.5 / 1.16=0.36$ for the voter information variable it is -0.065$)$.
} 
over all the states with limits is $\$ 1000$ and the median is $\$ 2000$. We can't reject the null hypothesis that the marginal effect of the law $\delta_{1}+\delta_{2} \ln \bar{C}_{i t}$ is zero for any of the states with limits below the median. But we can reject it for states with contribution limits above the median. The results for the restricted sample are similar except that the point estimate for the critical value is lower because the state excluded in the restricted sample, Nebraska, has an abnormally high cap of $\$ 73,000$, over three times the next highest cap and 30 times higher than the median.

In specification (2) in Table $2 \mathrm{~b}$ we estimate a more general form of $(2 \mathrm{E})$, namely $\kappa\left(\bar{C}_{i t}, \boldsymbol{\delta}\right)=$ $\delta_{1}+\delta_{2} \ln \bar{C}_{i t}+\delta_{3}\left(\ln \bar{C}_{i t}\right)^{2}+\delta_{4}\left(\ln \bar{C}_{i t}\right)^{3}$. The coefficients in this expression are not individually significant. However, they are jointly significant and therefore we calculate both a critical value and the marginal effects for different states. For states with caps above $\$ 2000$ we reject the null hypothesis of no effect on the number of lobbies. So, according to this specification, 23 of the 36 states with limits the cap significantly increased the number of lobbies.

The final point to note from Table 5 is that most states for which the predicted effect is not statistically significant set their limits in or before 1986. Had their laws allowed for the nominal values of their limits to be adjusted for inflation their limits would be higher today and therefore it could be possible for their effect to be significant (naturally this would also have implied a change in the estimated coefficients). The states that changed their limits during the sample period in our analysis typically have higher limits and therefore are more likely to have a significant effect.

\section{Conclusions}

The influence of money on elections and policy outcomes is a major public issue in democratic countries. A system with unregulated contributions provides a disproportionate amount of political power to individuals or groups with economic power or low cost of organizing. Limiting the amount that individuals or groups may contribute therefore appears to be a sensible reform. We have suggested, however, that caps on contributions, may in fact worsen the problem by providing an incentive for new lobbies to form. In this paper we provide a simple model to show when this outcome occurs and provide empirical evidence that caps have led to an increase in the number of lobbies in U.S. states.

The basic policy implication of the model is not that contribution caps should be abandoned as a part of campaign finance reform. Rather, if they are used they must either be sufficiently low or be complemented by measures that offset the gains to lobbying, thus reducing the incentive for new lobbies to form. One simple complementary reform is a proportional tax on contributions. If politicians value contributions more than social welfare, such a tax would reduce the marginal benefit 
of contributions to the politician and thus reduce the gains from lobbying. Hence, combining a cap with a tax can mitigate and even eliminate the potential for new lobby creation due to caps. Our model and the tax just described also have an important implication for the current policies that offer public funds to match private contributions to politicians who accept voluntary limits on spending. These matching funds work exactly as a subsidy to private contributions so they have the opposite effect of the tax scheme and will, according to our model, lead to lobby creation.

One potentially beneficial effect of caps is that it "levels" the playing field, that is it may limit the ability of lobbies that are better funded to have a disproportionate influence on policy. This has been one of the arguments put forward for caps. Our paper explores a downside to the caps that has been ignored: that it can increase the number of lobbies. If this increase occurs in policy areas where previously there wasn't much lobbying activity then it generates negative welfare effects since the policy will now respond to lobbying rather than simply social welfare. However, it is also possible that the new PACs that form in response to the cap lobby in policy areas in which other lobbies already operate. In the latter case lobby formation may have a positive social welfare effect if the interests of new lobbies are opposed to the ones of existing ones.

Our focus in the theory was motivated by the debate on restricting contributions. There are other ways of helping politicians, such as a PAC running an advertisement favoring the politician, or using some other non-monetary form to help him. Our conjecture is that if ads, for example, are a less efficient way of benefiting the politician than a cash transfer, then our results on the effect of restricting contributions would be similar. The reason is that as the more efficient form of transfer (cash) is restricted, more of the alternative form is used, but since the latter is relatively less efficient, it improves the bargaining position of the lobby. This insight is analogous to the results in Drazen and Limão (2004), who show how the government improves its bargaining position and can thus benefit by choosing a relatively less efficient policy to redistribute towards lobbies.

This suggests that an especially interesting extension would be to explicitly model elections and the use of contributions to fund political advertising, as in Prat (2002) and Coate (2004). As Coate shows, the welfare implications of restricting contributions depends on how they are used. If they are used to buy favors, as in our model, banning them may be socially optimal, while if they finance directly informative advertising about candidate quality, restricting them may actually lower social welfare. Moreover, when contributions finance policy favors, campaign advertising itself is less effective in conveying information on candidate quality. Our results raise the obvious question of how allowing the number of lobbies to change in response to campaign finance reform will affect the 
desirability or undesirability of limiting contributions that finance provision of information to voters.

There are other interesting avenues for future work. One is to analyze the impact of caps in the presence of lobbies that have asymmetries along dimensions other than organization costs, such as differences in bargaining power and lobby size. Although we do not expect the qualitative result of entry to change, the effect on total contributions and the amount of new distortions will certainly be different and it may generate additional interesting testable predictions. It would also be interesting to empirically test some of these predictions on industry or firm data to determine the importance of our channel on the probability of formation of corporate PACs relative to firm specific determinants.

Finally, a broader implication of our results is that modeling the endogenous response of lobby formation is crucial in evaluating the outcome of reforms. This is certainly true for political contributions but also applies to other political or economic reforms in areas where politicians and SIG interact. Such an analysis is particularly important when that interaction is characterized by bargaining since in those settings conventional wisdom and simple intuition often fail. 


\section{References}

Ansolabehere, S., J. de Figueiredo, and J. Snyder Jr. (2003), "Why is There so Little Money in U.S. Politics?," Journal of Economic Perspectives 17(1), 105-30.

Baron, D. (1994), "Electoral Competition with Informed and Uninformed Voters," American Political Science Review 88, 33-47.

Che, Y. and I. Gale (1998), "Caps on Political Lobbying," American Economic Review 88(3), 643-51.

Campaign Finance Law, Washington, DC: Federal Election Commission.

Coate, S. (2003), "Political Competition with Campaign Contributions and Informative Advertising," working paper, forthcoming in Journal of the European Economic Association.

55.

(2004), "Pareto Improving Campaign Finance Policy," American Economic Review. 94, 628-

Craig, G. (1978), Germany 1866-1945, Oxford: Oxford University Press.

Drazen, A. and N. Limão (2004), "Government Gains from Self-Restraint: A Bargaining Theory of Inefficient Redistribution," NBER Working Paper 10375.

Gray, V. and D. Lowery (1997), "Reconceptualizing PAC Formation: It's Not a Collective Action Problem, and It May Be an Arms Race," American Politics Quarterly 25(3), 319-346.

Grier, K.B., M.C. Munger, and B.E. Roberts (1994), "The Determinants of Industrial Political Activity, 1978-1986," American Political Science Review 88(4), 911-26.

Grossman, G. and E. Helpman (1994), "Protection for Sale," American Economic Review 84, 833-50. 265-286.

(1996), "Electoral Competition and Special Interest Politics," Review of Economic Studies 63,

Hall R.L. and Wayman F.W. (1990). "Buying Time: Moneyed Interests and the Mobilization of Bias in Congressional Committees," American Political Science Review 84(3), 797-820.

Hart, D. (2001), "Why Do Some Firms Give? Why Do Some Firms Give a Lot? High-Tech PACs, 1977-1996," Journal of Politics 63(4), 1230-1249.

Levitt, S. (1994), "Using Repeat Challengers to Estimate the Effects of Campaign Spending on Election Outcomes in the U.S. House," Journal of Political Economy 102, 777-798.

Mitra, D. (1999), "Endogenous Lobby Formation and Endogenous Protection: A Long-Run Model of Trade Policy Determination," American Economic Review 89(5), 1116-1134.

Pittman, R. (1988), "Rent-Seeking and Market Structure: Comment," Public Choice 58(2), 173-85.

Prat, A. (2002), "Campaign Advertising and Voter Welfare," Review of Economic Studies 69, 999-1018.

Riezman, R. and J.D. Wilson (1997), "Political Reform and Trade Policy," Journal of International Economics 42, 67-90.

Stratmann, T. (1998), "The Market for Congressional Votes: Is Timing of Contributions Everything?," Journal of Law and Economics 45 (1), 85-113.

(2003), "Can Special Interests Buy Congressional Votes? Evidence from Financial Services Legislation," Journal of Law and Economics 45(2), 345-375.

Trefler, D. (1993), "Trade Liberalization and the Theory of Endogenous Protection: An Econometric Study of U.S. Import Policy," Journal of Political Economy 101(1), 138-60.

Zardkoohi, A. (1988), "Market Structure and Campaign Contributions: Does Concentration Matter? A Reply," Public Choice 58(2), 187-91. 


\section{APPENDICES}

\section{A Derivation of (5) in an Electoral Framework}

This derivation follows Grossman and Helpman (1996). Suppose there are two parties, say $D$ and $R$, who choose vectors of production subsidies $\mathbf{t}^{D}$ and $\mathbf{t}^{R}$ to apply to the set of lobbies. Following Baron (1994) and Grossman and Helpman (1996), there are two types of voters, informed and uniformed. Informed voters choose on the basis of the parties' policies. Let the utility of informed voter $x$ from policy $\mathbf{t}^{P}$ be $w^{x}\left(\mathbf{t}^{P}\right)$. In addition party $R$ has exogenous characteristics (or immutable positions) which imply utility $\Re^{x}$ for informed voter $x$. Hence informed voter $x$ votes for party $D$ if and only if $w^{x}\left(\mathbf{t}^{D}\right)-w^{x}\left(\mathbf{t}^{R}\right) \geq \Re^{x}$. $\Re^{x}$ is not known to parties, but they know it is drawn from known distribution $F(\Re)$. Hence, the probability that voter $x$ votes for party $D$ is $F\left(w^{x}\left(\mathbf{t}^{D}\right)-w^{x}\left(\mathbf{t}^{R}\right)\right)$. Assume a continuum of informed voters of measure 1, so that by the law of large numbers, the fraction of informed voters who vote for party $D$ is $\int F\left(w^{x}\left(\mathbf{t}^{D}\right)-w^{x}\left(\mathbf{t}^{R}\right)\right) d x$, where the integral is taken over the set of informed voters.

Uniformed voters have utility over policies, but can be swayed by campaign advertisements. The fraction of uninformed voters who vote for party $D$ over party $R$ is assumed to depend on the difference in the campaign expenditures of the two parties, namely $S^{D}-S^{R}$, and is denoted $H\left(S^{D}-S^{R}\right)$. Hence if a fraction $\alpha$ of voters are uninformed and a fraction $1-\alpha$ are informed, the fraction of votes gained by party $D$ is

$$
\omega=(1-\alpha) \int F\left(w^{x}\left(\mathbf{t}^{D}\right)-w^{x}\left(\mathbf{t}^{R}\right)\right) d x+\alpha H\left(S^{D}-S^{R}\right)
$$

with party $R$ receiving a fraction $1-\omega$. Suppose that the objective of each party is to maximize its vote share.

Grossman and Helpman (1996) then assume specific functional forms for $F(\cdot)$ and $H(\cdot)$. As-

sume that $\Re$ is uniform over $\left(-\frac{1}{2 f}, \frac{1}{2 f}\right)$ for $f>0$, so that $F\left(w^{x}\left(\mathbf{t}^{D}\right)-w^{x}\left(\mathbf{t}^{R}\right)\right)=\frac{1}{2}+f \times$ $\left[w^{x}\left(\mathbf{t}^{D}\right)-w^{x}\left(\mathbf{t}^{R}\right)\right]$ for $w^{x}\left(\mathbf{t}^{D}\right)-w^{x}\left(\mathbf{t}^{R}\right)$ in this interval and $H\left(S^{D}-S^{R}\right)=\frac{1}{2}+h \times\left[S^{D}-S^{R}\right]$ for $h>0$. The vote fraction for party $D$ then becomes

$$
\omega=\frac{1}{2}+(1-\alpha) f \times\left[W\left(\mathbf{t}^{D}\right)-W\left(\mathbf{t}^{R}\right)\right]+\alpha h \times\left[S^{D}-S^{R}\right]
$$

where $W(\mathbf{t}) \equiv \int w^{x}(\mathbf{t}) d x$ is the average utility of informed voters if the vector of production subsidies is $\mathbf{t}$. Under the additional assumption that the distribution of utility functions among informed and uninformed voters is the same, once can think of $W(\cdot)$ as representing a social welfare function.

Suppose there is no lobby competition and lobby gives just enough to party $J$ to induce it to adopt policy $t_{i}^{J}$ (as will be the case here where lobbies know that voters have no ex ante bias towards either party). That is, suppose that lobbies have only a policy influence motive and no electoral motive, that is, no motive to try to influence election outcomes by influencing vote shares. Then $S^{J}=\sum_{i \in L} C_{i}^{J}$ for $J=D, R$ for $C_{i}$ as defined in the text. Each party chooses its platform $\mathbf{t}^{J}$ to maximize its vote share, taking the other party's platform as given. Party $D$, whose objective it is to maximize $\omega$, may then be seen as maximizing an objective

$$
D_{o}+\frac{(1-\alpha) f}{\alpha h} W\left(\mathbf{t}^{D}\right)+\sum_{i \in L} C_{i}^{D}
$$

where the constant $D_{o}=\frac{1}{2 \alpha h}-\left(\frac{(1-\alpha) f}{\alpha h} W\left(\mathbf{t}^{R}\right)+S^{R}\right)$. Party $R$, whose objective it is to maximize 
$1-\omega$, may then be seen as maximizing an objective

$$
R_{o}+\frac{(1-\alpha) f}{\alpha h} W\left(\mathbf{t}^{R}\right)+\sum_{i \in L} C_{i}^{R}
$$

where the constant $R_{o}=\frac{1}{2 \alpha h}-\left(\frac{(1-\alpha) f}{\alpha h} W\left(\mathbf{t}^{D}\right)+S^{D}\right)$.

When lobbies give just enough to the parties to induce them to adopt a policy, one can show (see Grossman and Helpman [1996]) that each party gets exactly half the votes, no matter what $\mathbf{t}^{D}$ and $\mathbf{t}^{R}$ are. If the probability that $\mathbf{t}^{D}$ is the outcome of the policy-making process is $\varphi(\omega)$ and the probability that $\mathbf{t}^{R}$ is the outcome is $1-\varphi(\omega)$ (where $\varphi\left(\frac{1}{2}\right)=\frac{1}{2}$ ), then each lobby $i$ makes an identical contribution to each party $\left(C_{i}^{R}=C_{i}^{D}=C_{i}\right)$ and $t_{i}^{R}=t_{i}^{D}$ for all $i$. That is, each party adopts the same platform $\left(\mathbf{t}^{D}=\mathbf{t}^{R}=\mathbf{t}\right)$ and $R_{o}=D_{o}$. Objectives (22) and (23) are obviously equivalent to (5) in the text when $W(\mathbf{t})$ is interpreted, as indicated, as the social welfare function.

Lobby $i$ 's objective in an electoral framework with contributions only to influence policy choices is

$$
V_{i}=\varphi(\omega) W_{i}\left(\mathbf{t}^{D}\right)+(1-\varphi(\omega)) W_{i}\left(\mathbf{t}^{R}\right)-C_{i}^{D}-C_{i}^{R}
$$

With $\omega=\frac{1}{2}$ and $\mathbf{t}^{D}=\mathbf{t}^{R}$, this is equivalent to (3) plus a constant (since the contribution made to one party is independent of the contribution to the other party.) With caps on the amount that can be given to each candidate (rather than on the total amount a lobby can give to all candidates), we can analyze contributions of lobbies to each candidate separately.

\section{B Proofs of Propositions}

\section{Proof of Proposition 1}

\section{i. Sufficiency}

Suppose that $\lambda \in(0,1)$. We need only show the existence of a cap $\overline{C_{i}}<C^{*}$ s.t. $V(\bar{C}, \bar{t})>$ $V\left(C^{*}, t^{*}\right)$. The solution is illustrated in Figure 2. We first show that the constrained Pareto frontier is strictly concave. The constrained Pareto frontier in Figure 2 coincides with the original one for $\overline{C_{i}} \geq C^{*}$ and thus its slope is simply $\frac{V_{C}}{G_{C}}=-1$ before the cap binds. From (6) we have $\frac{G_{t}}{G_{C}}=\frac{V_{t}}{V_{C}}$ at $N$ so that $\frac{V_{t}}{G_{t}}=\frac{V_{C}}{G_{C}}=-1$ when $\overline{C_{i}} \geq C^{*}$. The rest of the constrained frontier is strictly interior to the unconstrained one since by imposing a constraint on the problem in (8), we are reducing the total surplus when the constraint is binding. The slope of the Pareto frontier when the constraint binds is $\frac{V_{t}}{G_{t}}$, reflecting the ratio of changes in welfare as the amount of the production subsidy changes. Moreover, $\frac{V_{t}\left(t^{*}\right)}{G_{t}\left(t^{*}\right)}=-\frac{\pi^{\prime}}{a t \pi^{\prime \prime}}=-1>\frac{V_{t}\left(t<t^{*}\right)}{G_{t}\left(t<t^{*}\right)}$, where the first equality is due to the definitions of $G$ and $V$, the second follows from (7), and the inequality from noting that at the constrained optimum there are joint gains from increasing $t$ towards the unconstrained optimum $t^{*}$ (see Figure 1).

Now define point $A$ in Figure 2 as the intersection of the constrained frontier and $V=v^{N}$. Since the constrained frontier is strictly concave and $v^{m c}=v^{m}$ for $\overline{C_{i}} \geq C_{0}$, i.e. for all caps above the minimum contribution that maintains the government at $g^{0}$ given $t=t^{*}$ (see Figure 1), the segment connecting $v^{m}$ and $A$ is everywhere below the constrained Pareto frontier. Consider then an auxiliary problem where the Pareto frontier is defined by the straight line through $v^{m}$ and $A$, which has some slope $m$. For any linear Pareto frontier the lobby's equilibrium utility is $V^{*}-v^{0}=\lambda\left(v^{m}-v^{0}\right)$, which is easily shown by redefining (9) and confirming we again obtain (11). Since the straight line through $v^{m}$ and $A$ is a rotation of the original Pareto frontier inwards around $v^{m}$, and since $v^{m}-v^{0}$ and $\lambda$ are unchanged in the auxiliary problem, the equilibrium lobby utility is also unchanged. Therefore if we now re-derive the first-order condition, as we do for (8), we obtain $-\left.\frac{U_{G}}{U_{V}}\right|_{A}=m$. Strict concavity of the constrained frontier implies that at $A, m>\left.\frac{V_{t}}{G_{t}}\right|_{A}$, the slope of the constrained frontier at 
$A$. Therefore, the equilibrium point $N^{C}$ lies to the northwest of $A$, implying $v^{N c}>v^{N}$. Following a similar argument we can show that when $\lambda \in(0,1)$ we have $V(\bar{C}, \bar{t})>V\left(C^{*}, t^{*}\right)$ for any $\overline{C_{i}} \in\left[C_{0}, C^{*}\right)$.

Necessity: see part (ii)

ii. If $\lambda=1$ then the unconstrained solution is $v^{m} \equiv \operatorname{Max}_{C, t} V$ s.t. $G=g^{0}$. The equilibrium contribution is $C^{*}(\lambda=1)=C_{0}$. A strictly binding cap entails that the lobby's utility is now $v^{m c} \equiv \operatorname{Max}_{C, T} V$ s.t. $G=g^{0}$ and $\overline{C_{i}}<C^{*}$, the extra constraint implies that $v^{m c}<v^{m}$. If $\lambda=0$ then $V=v^{0}$ for any cap. This also proves the necessity of the condition $\lambda \in(0,1)$ in (i).

iii. From (11) we know $V^{*}>v^{0}$ if $\lambda \in(0,1]$. Since $\lim _{\bar{C} \longrightarrow 0} V(\bar{C}, t(\bar{C}))=v^{0}$ there exist sufficiently low caps s.t. $V(\bar{C}, t(\bar{C}))<V^{*}$. If $\lambda=0$ then $V=v^{0}$ for any cap.

iv. A binding cap $\overline{C_{j}} \in[0, \infty)$ changes the government's reservation utility in bargaining with $i$ to $g^{0 \prime}$ and it also changes its maximum utility to $g^{m \prime}$. The additive separability of policies in different sectors in $G$ implies that $t^{*}$ in 7 is unchanged. Therefore contributions are used as before to distribute the surplus $g^{m^{\prime}}-g^{0 \prime}$. But additive separability also implies that the change in $g^{m}$ and $g^{0}$ is identical so $g^{m^{\prime}}-g^{0 \prime}=g^{m}-g^{0}$. Moreover, since $v^{m}-v^{0}=g^{m}-g^{0}$ and $v^{0}=l_{i}+\pi(p)$ (recall $\alpha_{i} \longrightarrow 0$ ) we have that lobby $i$ 's utility, in (11) is unchanged.

\section{Proof of Proposition 2}

i. This follows immediately from (14), the definition of $F(n)$ with $F^{\prime}(n)>0$, and the independence of $V^{u}$ from caps and $n$.

ii. $\quad d(n(\bar{C}) C(\bar{C})) /(-d \bar{C})=\left(\varepsilon_{n \kappa}-1\right) n^{*}$, where. $\varepsilon_{n \kappa} \equiv(\ln (\bar{C}) /(-d \bar{C})) /\left(n^{*} / C^{*}\right)$. Now $\varepsilon_{n \kappa}>1 \mathrm{iff}(\operatorname{dn}(\bar{C}) /(-d \bar{C})) /\left(n^{*} / C^{*}\right)>1 \Leftrightarrow\left(\frac{d V /(-d \bar{C})}{F^{\prime}\left(n^{*}\right)}\right) /\left(n^{*} / C^{*}\right)>1$, where we use (14) to obtain $d n(\bar{C}) /(-d \bar{C})=\frac{d V /(-d \bar{C})}{F^{\prime}(n)}$. Since both $d V /(-d \bar{C})$ and $C^{*}$ are independent of $n$ the condition is satisfied if $F^{\prime}\left(n^{*}\right)$ is sufficiently low. Alternatively if $F(n=0)$ is sufficiently high then, from (14), the initial number of lobbies $n^{*}$ is sufficiently low and $\varepsilon_{n \kappa}>1$.

iii. The effect of tightening the cap on the total level of subsidies for the set of lobbies $L^{\prime}$ that includes the previously and newly organized sectors is

$$
\begin{aligned}
\left.\frac{d\left[\sum_{i \in L^{\prime}} t_{i} \pi^{\prime}\right]}{-d \bar{C}}\right|_{C=C^{*}} & =n^{*} \frac{d\left[t(\bar{C}) \pi^{\prime}(p+t(\bar{C}))\right]}{-d \bar{C}}+\frac{d n(\bar{C})}{(-d \bar{C})} t(\bar{C}) \pi^{\prime}(p+t(\bar{C})) \\
& =\frac{n^{*}\left(t(\bar{C}) \pi^{\prime}(p+t(\bar{C}))\right)}{C^{*}}\left(\varepsilon_{T \kappa}+\varepsilon_{n \kappa}\right)
\end{aligned}
$$

where $\varepsilon_{T \kappa} \equiv \frac{d\left[t(\bar{C}) \pi^{\prime}(p+t(\bar{C}))\right]}{-d \bar{C}} \frac{C^{*}}{t(\bar{C}) \pi^{\prime}(p+t(\bar{C}))}$. Since $\frac{n^{*}\left(t(\bar{C}) \pi^{\prime}(p+t(\bar{C}))\right)}{C^{*}}>0$, we have $\operatorname{sign}\left(\left.\frac{d\left[\sum_{i \in L^{\prime}} t_{i} \pi^{\prime}\right]}{-d \bar{C}}\right|_{C=C^{*}}\right)=$ $\operatorname{sign}\left(\varepsilon_{T \kappa}+\varepsilon_{n \kappa}\right)$.

Rewriting in terms of the elasticity of the subsidy rate, $\varepsilon_{t \kappa} \equiv \frac{d t(\bar{C})}{-d \bar{C}} \frac{C^{*}}{t(\bar{C})}$, we have:

$$
\begin{aligned}
& \left.\varepsilon_{T \kappa}\right|_{C=C^{*}}=\left.\frac{d\left[t(\bar{C}) \pi^{\prime}(p+t(\bar{C}))\right]}{-d \bar{C}} \frac{C^{*}}{t(\bar{C}) \pi^{\prime}(p+t(\bar{C}))}\right|_{C=C^{*}} \\
& =\frac{d t(\bar{C})}{-d \bar{C}} \frac{C^{*}}{t(\bar{C})}\left(\left.\left(1+\frac{t(\bar{C}) \pi^{\prime \prime}(p+t(\bar{C}))}{\pi^{\prime}(p+t(\bar{C}))}\right)\right|_{C=C^{*}}\right. \\
& =\left.\varepsilon_{t \kappa}\left(1+\frac{t(\bar{C}) \pi^{\prime \prime}(p+t(\bar{C}))}{\pi^{\prime}(p+t(\bar{C}))}\right)\right|_{C=C^{*}} \\
& =\varepsilon_{t \kappa}\left(1+\frac{1}{a}\right)
\end{aligned}
$$

Therefore

$$
\operatorname{sign}\left(\left.\frac{d\left[\sum_{i \in L^{\prime}} t_{i} \pi^{\prime}\right]}{-d \bar{C}}\right|_{C=C^{*}}\right)=\operatorname{sign}\left(\varepsilon_{t \kappa}\left(1+\frac{1}{a}\right)+\varepsilon_{n \kappa}\right)
$$


Since $\varepsilon_{T \kappa}$ is independent of $n$ the condition $\varepsilon_{T \kappa}+\varepsilon_{n \kappa}>0$ is satisfied if either $F^{\prime}\left(n^{*}\right)$ is sufficiently low or $F(n=0)$ is sufficiently high.

iv. All derivatives, $\pi^{\prime}, \pi^{\prime \prime}$ evaluated at $p+t(\bar{C})$.

$$
\begin{aligned}
\frac{d W}{-d \bar{C}} & =\frac{d\left[\sum_{i \in L^{\prime}} \pi(p+t(\bar{C}))\right]}{-d \bar{C}}-\left.\frac{d\left[\sum_{i \in L^{\prime}} t_{i} \pi^{\prime}\right]}{-d \bar{C}}\right|_{C=C^{*}} \\
& =n^{*} \frac{d \pi(p+t(\bar{C}))}{d t} \frac{d t}{-d \bar{C}}+\frac{d n(\bar{C})}{(-d \bar{C})}(\pi(p+t(\bar{C}))-\pi(p))-\left.\frac{n^{*}\left(t(\bar{C}) \pi^{\prime}\right.}{C^{*}}\left(\varepsilon_{T \kappa}+\varepsilon_{n \kappa}\right)\right|_{C=C^{*}} \\
& =\left.\frac{n^{*}\left(t(\bar{C}) \pi^{\prime}\right.}{C^{*}}\left(\varepsilon_{t \kappa}+\frac{1}{t \pi^{\prime}} \varepsilon_{n \kappa}(\pi(p+t(\bar{C}))-\pi(p))-\left(\varepsilon_{T \kappa}+\varepsilon_{n \kappa}\right)\right)\right|_{C=C^{*}} \\
& =\left.\frac{n^{*}}{C^{*}}\left\{\left(\varepsilon_{t \kappa} / \varepsilon_{T \kappa}-1\right) \varepsilon_{T \kappa} t \pi^{\prime}+\varepsilon_{n \kappa}\left(\pi(p+t(\bar{C}))-\pi(p)-t \pi^{\prime}\right)\right\}\right|_{C=C^{*}} \\
& =\left.\frac{n^{*}}{C^{*}}\left\{\left(\frac{1}{1+\frac{t \pi^{\prime \prime}}{\pi^{\prime}}}-1\right) \varepsilon_{T \kappa} t \pi^{\prime}+\varepsilon_{n \kappa}\left(\pi(p+t(\bar{C}))-\pi(p)-t \pi^{\prime}\right)\right\}\right|_{C=C^{*}} \\
& =\frac{n^{*}}{C^{*}}\left\{-\varepsilon_{T \kappa} \frac{t^{* 2} \pi^{\prime \prime}}{1+\frac{t^{*} \pi^{\prime \prime}}{\pi^{\prime}}}+\varepsilon_{n \kappa}\left(\pi\left(p+t^{*}\right)-\pi(p)-t^{*} \pi^{\prime}\right)\right\} \\
& =\frac{n^{*}}{C^{*}}\left\{-\varepsilon_{t \kappa} t^{* 2} \pi^{\prime \prime}+\varepsilon_{n \kappa}\left(\pi\left(p+t^{*}\right)-\pi(p)-t^{*} \pi^{\prime}\right)\right\}
\end{aligned}
$$

Note that in the second equality we have $\frac{d\left[\sum_{i \in L^{\prime}} \pi(p+t(\bar{C}))\right]}{-d \bar{C}}=n^{*} \frac{d \pi(p+t(\bar{C}))}{d t} \frac{d t}{-d \bar{C}}+\frac{d n(\bar{C})}{(-d \bar{C})}(\pi(p+t(\bar{C}))-$ $\pi(p))$. The last term corresponds to the increase in profits for the lobbies that were previously unorganized and thus had profits of $\pi(p)$. Since $\varepsilon_{T \kappa}, t^{*}, \pi\left(p+t^{*}\right)$ and $\pi(p)$ are independent of $n$ and $-\left(\pi\left(p+t^{*}\right)-\pi(p)-t^{*} \pi^{\prime}\right)>0$ (the additional profit form the subsidy is more than offset by the cost of the subsidy) the condition $\varepsilon_{n \kappa}\left(-\left(\pi\left(p+t^{*}\right)-\pi(p)-t^{*} \pi^{\prime}\right)\right)>-\varepsilon_{T \kappa} \frac{t^{* 2} \pi^{\prime \prime}}{1+\frac{t^{*} \pi^{\prime \prime}}{\pi^{\prime}}}$ is satisfied when $\varepsilon_{n \kappa}$ is sufficiently large, which occurs if either $F^{\prime}\left(n^{*}\right)$ is sufficiently low or $F(n=0)$ is sufficiently high.

\section{Proof of Proposition 3}

Consider a cap that is binding in the absence of a tax on contributions $\left(\bar{C}<C^{*}\right)$. Let the tax on contributions be defined as in (18). A uniform tax on contributions will lower the equilibrium contribution, which we denote $C^{\mu} \equiv C(\mu(C), \bar{C})$, with $n^{\mu}$ and $t^{\mu}$ defined analogously. There are two cases to consider, depending on whether $C^{\mu}>\bar{C}$ or $C^{\mu} \leq \bar{C}$.

\section{Case a: $C^{\mu} \leq \bar{C}$ (Cap does not bind)}

i. Unorganized lobbies face no change in prices or subsidies or labor endowment so $V^{u}(\mu(C), \bar{C})=$ $V^{u *}$. To determine the maximized objective of organized lobbies we use (8) but rewrite the Pareto frontier in (9). the frontier is still linear because transfers take place through $C$ which enters $G$ and $V$ linearly. But now $v^{m \mu}<v^{m}$ and $g^{m \mu}<g^{m}$ because the government requires higher contributions to remain indifferent to a given subsidy.

$$
V=v^{m \mu}-\left(G-g^{0}\right) /(1-(1-a(1-\beta)) \bar{\mu})
$$

It is simple to verify that the linear frontier in (25) still implies a solution of the same form as (10) and (11) but now, since $v^{m \mu}<v^{m}$ and $g^{m \mu}<g^{m}$ and $g^{0}, v^{0}$ and $\lambda$ are unchanged we have

$$
\begin{aligned}
G^{* \mu}-g^{0} & =(1-\lambda)\left(g^{m \mu}-g^{0}\right)<G^{*}-g^{0} \\
V^{* \mu}-v^{0} & =\lambda\left(v^{m \mu}-v^{0}\right)<V^{*}-v^{0}
\end{aligned}
$$

where $V^{* \mu} \equiv V(\mu(C), \bar{C}) \leq V^{*}$. Since $V^{u}(\mu(C), \bar{C})=V^{u *}$, no new lobbies form because, according to (14), prior to the reform all unorganized lobbies have $V^{*}-V^{u *}<F\left(n^{*}\right)$. 
ii. The equilibrium contribution $C^{\mu}$ satisfies $C^{\mu} \leq \bar{C}<C^{*}$ so that $n^{\mu} C^{\mu}<n^{*} C^{*}$ since $n^{\mu}=n^{*}$. iii. The subsidy rate is defined similarly to (7) so that we have for each lobby $G_{t} / G_{C}=V_{t} / V_{C}$

$$
\begin{gathered}
G_{t} / G_{C}=-a t^{\mu} \pi^{\prime \prime}\left(t^{\mu}\right) /(1-(1-a(1-\beta)) \bar{\mu}) \\
V_{t} / V_{C}=-\pi^{\prime}\left(t^{\mu}\right) \\
\frac{\left.t^{\mu} \pi^{\prime \prime}\left(t^{\mu}\right)\right)}{\left.\pi^{\prime}\left(t^{\mu}\right)\right)}=\frac{1-(1-a(1-\beta)) \bar{\mu}}{a}
\end{gathered}
$$

From (7) we have $\frac{t^{*} \pi^{\prime \prime}\left(p+t^{*}\right)}{\pi^{\prime}\left(p+t^{*}\right)}=\frac{1}{a}$. Assuming $a<1$ implies $1-(1-a(1-\beta)) \bar{\mu} \leq 1$ for $\bar{\mu} \geq 0$. Thus, from (28), as $\bar{\mu} \rightarrow 0, t^{\mu} \rightarrow t^{*-}$ and as $\bar{\mu} \rightarrow \frac{1}{1-a(1-\beta)}^{-}, t^{\mu} \rightarrow 0^{+}$. So for $\bar{\mu}>0$ we have $t^{\mu}<t^{*}$. Moreover, since $\pi^{\prime \prime}>0$ implies $\pi^{\prime}\left(p+t_{i}^{\mu}\right)<\pi^{\prime}\left(p+t_{i}^{*}\right)$, with no change in $n$, we also have $\sum_{i \in L} t_{i}^{\mu} \pi^{\prime}\left(p+t_{i}^{\mu}\right)<\sum_{i \in L} t_{i}^{*} \pi^{\prime}\left(p+t_{i}^{*}\right)$.

iv. With no new lobby formation the change in social welfare reflects the reduction in taxes $\sum_{i \in L} t_{i}^{*} \pi^{\prime}\left(p+t_{i}^{*}\right)-t_{i}^{\mu} \pi^{\prime}\left(p+t_{i}^{\mu}\right)$ which more than offsets the lost profit from the lower subsidy rate, and the redistributed contribution tax revenue per lobby $\sum_{i \in L}(1-\beta) \bar{\mu} C^{\mu}$, both of which imply higher social welfare.

$$
\begin{aligned}
& \sum_{i \in L}\left\{\pi\left(p+t_{i}^{\mu}\right)-t_{i}^{\mu} \pi^{\prime}\left(p+t_{i}^{\mu}\right)+(1-\beta) \bar{\mu} C^{\mu}\right\}-\sum_{i \in L}\left\{\pi\left(p+t_{i}^{*}\right)-t_{i}^{*} \pi^{\prime}\left(p+t_{i}^{*}\right)\right\} \\
= & \sum_{i \in L}\left\{t_{i}^{*} \pi^{\prime}\left(p+t_{i}^{*}\right)-t_{i}^{\mu} \pi^{\prime}\left(p+t_{i}^{\mu}\right)+(1-\beta) \bar{\mu} C^{\mu}\right\}-\sum_{i \in L}\left\{\pi\left(p+t_{i}^{*}\right)-\pi\left(p+t_{i}^{\mu}\right)\right\}>0
\end{aligned}
$$

\section{Case (b): $C^{\mu}>\bar{C}$ (Cap binds)}

When the cap is zero and $\lambda>0$ the lobby is worse off under the cap. Moreover, in Proposition 1 , we show there is a binding cap that leaves the lobby better off for $\lambda \in(0,1)$. Therefore there is a critical value of a binding cap that leaves the lobby indifferent relative to the unconstrained political equilibrium level $V^{*}$. If $\bar{C}$ is below that critical value then we can simply take $\bar{\mu}=0$ to obtain:

i. $V(\bar{\mu}, \bar{C}) \leq V^{*}$ and $V^{u}(\bar{\mu}, \bar{C})=V^{u *}$ so that no new lobbies form.

ii. The equilibrium contribution is $\bar{C}$. Therefore $C^{*}>\bar{C}=C^{\mu} \Longrightarrow n^{\mu} C^{\mu}<n^{*} C^{*}$.

iii. As is clear from Figure 1, there is a fall in the unit production subsidy $t$ and in total subsidies since $\pi^{\prime \prime}>0 \Longrightarrow \pi^{\prime}\left(p+t_{i}^{\mu}\right)<\pi^{\prime}\left(p+t_{i}^{*}\right)$.

iv. Similarly to case (a) the reduction in subsidies increases social welfare, but now there is no contribution tax revenue collected.

If $\bar{C}$ is above that critical value and below $C^{*}$ then, when $\bar{\mu}=0$, the effects in Propositions 1 and 2 are present. Therefore we must show that a rate $\bar{\mu} \in\left(0, \frac{1}{1-a(1-\beta)}\right)$ exists such that i-iv are satisfied.

Define the rate $\widehat{\mu}$ s.t. $v^{m \mu}(\bar{\mu}=\widehat{\mu})=V^{*}$. To prove the existence of a $\widehat{\mu} \in\left(0, \frac{1}{1-a(1-\beta)}\right)$ note that $\lim _{\widehat{\mu} \rightarrow 0} v^{m \mu}=v^{m}(\bar{C})>V^{*}(\bar{C})$ where the first equality is due to the equivalence between the tax rate for $C>\bar{C}$ and a cap of $\bar{C}$ and the last inequality is due to $\lambda \in(0,1)$. Second, $\lim _{\widehat{\mu} \rightarrow \frac{1}{1-a(1-\beta)}}-v^{m \mu}=v^{0}<V^{*}(\bar{C})$ where the first equality is due to $\lim _{\widehat{\mu} \rightarrow \frac{1}{1-a(1-\beta)}}-G_{C}=0$ and the last inequality is due to $\lambda \in(0,1)$. Therefore since $v^{m \mu}$ is continuous in $\bar{\mu}$ (recall $v^{m \mu}$ is the maximum lobby utility that maintains $\left.G(\bar{\mu},)=.g^{0}\right)$ a $\widehat{\mu} \in\left(0, \frac{1}{1-a(1-\beta)}\right)$ exists.

i. From the definition of $\widehat{\mu}$ and $v^{m \mu}$ we have that at $\bar{\mu}=\widehat{\mu}$, so that $V(\mu(\bar{C}), \bar{C}) \leq v^{m \mu}(\cdot)=V^{*}$. Moreover $V^{u}(\mu(C), \bar{C})=V^{u *}$. Thus no new lobbies form because, according to (14), prior to the reform all unorganized lobbies have $V^{*}-V^{u *}<F\left(n^{*}\right)$.

The proof for ii,iii and iv follows exactly as shown above. 
Table 1a

Summary statistics

\begin{tabular}{lrrrr}
\hline \hline Variable & Mean & Std. Dev. & \multicolumn{1}{c}{ Min } & \multicolumn{1}{c}{ Max } \\
\hline $\ln n$ (PACs) & 3.70 & 1.16 & 0 & 6.18 \\
$\ln n$ (Sponsors) & 3.63 & 1.13 & 0 & 6.13 \\
$1(C)$ & 0.54 & 0.50 & 0 & 1 \\
$1(C)^{*} \ln C$ & 4.30 & 4.04 & 0 & 11.20 \\
Prohib_corp_union & 0.67 & 0.83 & 0 & 2 \\
hhi $[\lambda]$ & 0.04 & 0.01 & 0.03 & 0.08 \\
reg_con & 0.008 & 0.008 & 0.0008 & 0.006 \\
Ln voter information $[a]$ & -0.468 & 0.115 & -0.775 & -0.47 \\
Lnpop & 8.07 & 1.01 & 6.12 & 10.42 \\
lny_capita & 10.07 & .17 & 9.61 & 10.57 \\
lny_taxes & 15.61 & 1.16 & 13.26 & 18.81 \\
\hline
\end{tabular}

Obs. 399. VT had no registered federal PACs in 1996.

Table $1 \mathrm{~b}$

Summary statistics for restricted sample and excluded instruments

\begin{tabular}{lrrrr}
\hline \hline Variable & Mean & Std. Dev. & Min & \multicolumn{1}{c}{ Max } \\
\hline $\ln n$ (PACs) & 3.70 & 1.17 & 0 & 6.18 \\
\hline $\ln n$ (Sponsors) & 3.64 & 1.14 & 0 & 6.13 \\
$1(C)$ & 0.54 & 0.50 & 0 & 1 \\
$1(C)^{*} \ln C$ & 4.25 & 4.00 & 0 & 9.90 \\
Prohib_corp_union & 0.68 & 0.83 & 0 & 2 \\
hhi [ $\lambda]$ & 0.36 & 0.01 & 0.27 & 0.08 \\
reg_con [c] & 0.008 & 0.008 & 0.0008 & 0.041 \\
Ln voter information $[a]$ & -0.467 & 0.115 & -0.775 & -0.47 \\
Lnpop & 8.09 & 1.01 & 6.12 & 10.42 \\
lny_capita & 10.07 & .17 & 9.61 & 10.57 \\
lny_taxes & 15.63 & 1.17 & 13.26 & 18.81 \\
\hline dem1 & 0.56 & 0.17 & 0.13 & 0.95 \\
dem1sq & 0.34 & 0.19 & 0.02 & 0.90 \\
chdem1 & -0.01 & 0.06 & -0.32 & 0.29 \\
Demgov & 0.48 & 0.50 & 0 & 1 \\
Chdemgov & -0.04 & 0.41 & -1 & 1 \\
Chdemgovx chdem1 & 0.00 & 0.02 & -0.17 & 0.12 \\
Lntransf_capita_lag & 16.12 & 1.07 & 13.84 & 18.57 \\
Initcliberal & 22.00 & 25.36 & 0 & 93.91 \\
Initiative & 0.47 & 0.50 & 0 & 1 \\
cit6099 & 48.71 & 14.64 & 9.25 & 93.91 \\
\hline Obs 391. VT & &
\end{tabular}

Obs. 391. VT had no registered federal PACs in 1996. Legislators to the unicameral legislature in Nebraska are non-partisan. Thus some of our instruments reflecting the make-up and change of the legislature do not exist for Nebraska. 
Table $2 \mathrm{a}$

Contribution limits as a determinant of the number of PACs: average effect

(OLS estimates within US states: 1986-2000)

\begin{tabular}{|c|c|c|c|c|c|c|}
\hline & (1) PACs & (2) PACs & (1) Sponsor & (2) Sponsor & (1r) PAC & (2r) PAC \\
\hline $1(C)$ & $\begin{array}{l}0.084 * * * \\
(0.026)\end{array}$ & $\begin{array}{l}0.073 * * * \\
(0.025)\end{array}$ & $\begin{array}{l}0.084 * * * \\
(0.026)\end{array}$ & $\begin{array}{l}0.071 * * * \\
(0.025)\end{array}$ & $\begin{array}{l}0.073 * * * \\
(0.027)\end{array}$ & $\begin{array}{l}0.061 * * \\
(0.026)\end{array}$ \\
\hline Prohib_corp_union & & $\begin{array}{l}0.068 * \\
(0.040)\end{array}$ & & $\begin{array}{l}0.077 * * \\
(0.035)\end{array}$ & & $\begin{array}{l}0.070^{*} \\
(0.040)\end{array}$ \\
\hline hhi $[\lambda]$ & $\begin{array}{l}10.576 \\
(27.485)\end{array}$ & $\begin{array}{l}9.723 \\
(27.625)\end{array}$ & $\begin{array}{l}5.368 \\
(26.726)\end{array}$ & $\begin{array}{l}4.405 \\
(26.913)\end{array}$ & $\begin{array}{l}11.281 \\
(27.649)\end{array}$ & $\begin{array}{l}10.505 \\
(27.806)\end{array}$ \\
\hline hhi squared & $\begin{array}{l}-297.648 \\
(303.105)\end{array}$ & $\begin{array}{l}-303.1 \\
(304.0)\end{array}$ & $\begin{array}{l}-280.9 \\
(289.5)\end{array}$ & $\begin{array}{l}-287.2 \\
(291.1)\end{array}$ & $\begin{array}{l}-301.9 \\
(305.0)\end{array}$ & $\begin{array}{l}-308.5 \\
(306.2)\end{array}$ \\
\hline reg_con $[c]$ & $\begin{array}{l}3.077 \\
(4.583)\end{array}$ & $\begin{array}{l}4.254 \\
(4.626)\end{array}$ & $\begin{array}{l}5.861 \\
(4.515)\end{array}$ & $\begin{array}{l}7.206 \\
(4.651)\end{array}$ & $\begin{array}{l}2.31 \\
(4.554)\end{array}$ & $\begin{array}{l}3.492 \\
(4.601)\end{array}$ \\
\hline Ln voter info $[a]$ & $\begin{array}{l}-0.656^{* *} \\
(0.268)\end{array}$ & $\begin{array}{l}-0.606^{* *} \\
(0.267)\end{array}$ & $\begin{array}{l}-0.636 * * \\
(0.278)\end{array}$ & $\begin{array}{l}-0.579 * * \\
(0.278)\end{array}$ & $\begin{array}{l}-0.689 * * \\
(0.266)\end{array}$ & $\begin{array}{l}-0.640 * * \\
(0.265)\end{array}$ \\
\hline lnpop & $\begin{array}{l}0.047 \\
(0.295)\end{array}$ & $\begin{array}{l}0.02 \\
(0.286)\end{array}$ & $\begin{array}{l}0.106 \\
(0.299)\end{array}$ & $\begin{array}{l}0.075 \\
(0.291)\end{array}$ & $\begin{array}{l}0.099 \\
(0.297)\end{array}$ & $\begin{array}{l}0.073 \\
(0.287)\end{array}$ \\
\hline lny_capita & $\begin{array}{l}1.190 * * * \\
(0.450)\end{array}$ & $\begin{array}{l}1.166^{* *} \\
(0.454\end{array}$ & $\begin{array}{l}0.958 * * \\
(0.439)\end{array}$ & $\begin{array}{l}0.931 * * \\
(0.442)\end{array}$ & $\begin{array}{l}1.201 * * * \\
(0.453)\end{array}$ & $\begin{array}{l}1.175^{* *} \\
(0.459)\end{array}$ \\
\hline lny_taxes & $\begin{array}{l}-0.252 \\
(0.188)\end{array}$ & $\begin{array}{r}-0.224 \\
(0.176\end{array}$ & $\begin{array}{l}-0.244 \\
(0.179) \\
\end{array}$ & $\begin{array}{l}-0.213 \\
(0.169)\end{array}$ & $\begin{array}{l}-0.264 \\
(0.188)\end{array}$ & $\begin{array}{l}-0.235 \\
(0.176) \\
\end{array}$ \\
\hline Observations & 399 & 399 & 398 & 398 & 391 & 391 \\
\hline R-squared $^{1}$ & 0.50 & 0.51 & 0.60 & 0.61 & 0.51 & 0.52 \\
\hline
\end{tabular}

Robust standard errors in parentheses. * Significant at 10\%; ** significant at 5\%;*** significant at $1 \%$. State and year effects included in all specifications but not reported.

1. The R-squared refers to the regression using deviations from the state means. 
Table $2 b$

Contribution limits as a determinant of the number of PACs: non-linear effects

(OLS estimates within US states: 1986-2000)

\begin{tabular}{|c|c|c|c|c|}
\hline & (1) & (2) & (1r) & $(2 r)$ \\
\hline \multirow[t]{2}{*}{$1(C)$} & $-0.280 * *$ & -2.18 & $-0.222^{*}$ & $-6.826^{*}$ \\
\hline & $(0.113)$ & (2.198) & $(0.129)$ & $(4.076)$ \\
\hline \multirow{2}{*}{$1(C)^{*} \ln C$} & $0.043 * * *$ & 0.84 & $0.036^{* *}$ & $2.783^{*}$ \\
\hline & $(0.013)$ & $(0.826)$ & $(0.015)$ & (1.64) \\
\hline \multirow[t]{2}{*}{$1(C)^{*}(\ln C)^{2}$} & & -0.108 & & $-0.374 *$ \\
\hline & & $(0.100)$ & & $(0.217)$ \\
\hline \multirow[t]{2}{*}{$1(C)^{*}(\ln C)^{3}$} & & 0.005 & & $0.017^{*}$ \\
\hline & & $(0.004)$ & & (0.009) \\
\hline \multirow[t]{2}{*}{ hhi $[\lambda]$} & 14.44 & 14.389 & 13.677 & 12.667 \\
\hline & (26.712) & (27.052) & (26.902) & (27.099) \\
\hline \multirow[t]{2}{*}{ hhi squared } & -320.187 & -324.766 & -314.26 & -316.07 \\
\hline & (294.684) & (299.29) & (296.47) & (297.13) \\
\hline \multirow{2}{*}{ reg_con $[c]$} & 2.63 & 2.286 & 2.257 & 1.879 \\
\hline & $(4.301)$ & $(4.430)$ & (4.344) & $(4.427)$ \\
\hline \multirow{2}{*}{ Ln voter info $[a]$} & $-0.584 * *$ & $-0.634 * *$ & $-0.605^{* *}$ & $-0.614 * *$ \\
\hline & $(0.273)$ & $(0.276)$ & $(0.280)$ & $(0.280)$ \\
\hline \multirow[t]{2}{*}{ Lnpop } & 0.027 & 0.058 & 0.064 & 0.061 \\
\hline & $(0.291)$ & $(0.294)$ & $(0.294)$ & $(0.294)$ \\
\hline \multirow[t]{2}{*}{ lny_capita } & $1.149 * *$ & $1.155^{* *}$ & $1.173 * *$ & $1.186^{* * *}$ \\
\hline & $(0.452)$ & $(0.453)$ & $(0.455)$ & $(0.457)$ \\
\hline \multirow[t]{2}{*}{ lny_taxes } & -0.248 & -0.258 & -0.258 & -0.289 \\
\hline & $(0.188)$ & $(0.187)$ & $(0.189)$ & $(0.189)$ \\
\hline Observations & 399 & 399 & 391 & 391 \\
\hline $\mathrm{R}_{\text {-squared }}{ }^{1}$ & 0.51 & 0.51 & 0.51 & 0.52 \\
\hline Critical value $^{2}$ & $\$ 673$ & $\$ 234$ & $\$ 477$ & $\$ 278$ \\
\hline Joint sig $p^{3}$ & 0.00 & 0.00 & 0.00 & 0.00 \\
\hline
\end{tabular}

Robust standard errors in parentheses. .* Significant at 10\%; ** significant at 5\%;** significant at $1 \%$. State and year effects included in all specifications but not reported.

1. The R-squared refers to the regression using deviations from the state means.

2. Contribution caps above this value imply larger number of PACs relative to no cap.

3. Probability value of joint test of significance of the coefficients in $\left(\delta_{1}+\delta_{2} \ln C\right)^{*} 1(C)_{\text {it }}$ for $(1)$ and $(1 \mathrm{r})$ and $\left(\delta_{1}+\delta_{2} \ln C+\right.$ $\left.\delta_{3}(\operatorname{lnC})^{2}+\delta_{4}(\ln C)^{3}\right)^{*} 1(C)_{\mathrm{it}}$ for $(2)$ and $(2 \mathrm{r})$. 
Table 3

Contribution limits as a determinant of the number of PACs (IV-GMM estimates within US states: 1986-2000)

\begin{tabular}{|c|c|c|c|c|}
\hline & \multicolumn{2}{|l|}{ Table $2 \mathrm{a}$} & \multicolumn{2}{|c|}{ Table $2 \mathrm{~b}$} \\
\hline & (1) & (2) & (3) & (4) \\
\hline $1(C)^{\dagger}$ & $\begin{array}{l}0.286^{* * *} \\
(0.110)\end{array}$ & $\begin{array}{l}0.298 * * * \\
(0.106)\end{array}$ & $\begin{array}{l}-0.057 \\
(0.757)\end{array}$ & $\begin{array}{l}-39.224 \\
(37.174)\end{array}$ \\
\hline Prohib_corp_union ${ }^{*}$ & & $\begin{array}{l}0.041 \\
(0.035)\end{array}$ & & \\
\hline $1(C)^{*} \ln C^{\dagger}$ & & & $\begin{array}{l}0.036 \\
(0.078)\end{array}$ & $\begin{array}{l}14.72 \\
(15.104)\end{array}$ \\
\hline $1(C)^{*}(\ln C)^{2 \dagger}$ & & & & $\begin{array}{l}-1.815 \\
(2.034)\end{array}$ \\
\hline $1(C)^{*}(\ln C)^{3 \dagger}$ & & & & $\begin{array}{l}0.074 \\
(0.091)\end{array}$ \\
\hline hhi $[\lambda]$ & $\begin{array}{l}0.638 \\
(26.481)\end{array}$ & $\begin{array}{l}-2.122 \\
(26.359)\end{array}$ & $\begin{array}{l}8.258 \\
(28.763)\end{array}$ & $\begin{array}{l}-0.534 \\
(36.802)\end{array}$ \\
\hline hhi squared & $\begin{array}{l}-240.874 \\
(270.062)\end{array}$ & $\begin{array}{l}-225.603 \\
(269.088)\end{array}$ & $\begin{array}{l}-293.403 \\
(272.624)\end{array}$ & $\begin{array}{l}-214.431 \\
(321.414)\end{array}$ \\
\hline reg_con $[c]$ & $\begin{array}{l}0.483 \\
(4.025)\end{array}$ & $\begin{array}{l}1.168 \\
(4.065)\end{array}$ & $\begin{array}{l}1.061 \\
(3.658)\end{array}$ & $\begin{array}{l}6.339 \\
(8.447)\end{array}$ \\
\hline ln voter info $[a]$ & $\begin{array}{l}-0.557 * * \\
(0.233)\end{array}$ & $\begin{array}{l}-0.527 * * \\
(0.232)\end{array}$ & $\begin{array}{l}-0.466^{*} \\
(0.283)\end{array}$ & $\begin{array}{l}-0.305 \\
(0.346)\end{array}$ \\
\hline Lnpop & $\begin{array}{l}-0.096 \\
(0.236)\end{array}$ & $\begin{array}{l}-0.118 \\
(0.233)\end{array}$ & $\begin{array}{l}-0.089 \\
(0.238)\end{array}$ & $\begin{array}{l}0.002 \\
(0.275)\end{array}$ \\
\hline lny_capita & $\begin{array}{l}1.189 * * * \\
(0.385)\end{array}$ & $\begin{array}{l}1.178 * * * \\
(0.389)\end{array}$ & $\begin{array}{l}1.206^{* * * *} \\
(0.374)\end{array}$ & $\begin{array}{l}1.245^{* * *} \\
(0.388)\end{array}$ \\
\hline lny_taxes & $\begin{array}{l}-0.294 * \\
(0.154)\end{array}$ & $\begin{array}{l}-0.291 * \\
(0.154)\end{array}$ & $\begin{array}{l}-0.300^{* *} \\
(0.146)\end{array}$ & $\begin{array}{l}-0.256 \\
(0.239)\end{array}$ \\
\hline Observations & 391 & 391 & 391 & 391 \\
\hline Hansen's J p ${ }^{1}$ & 0.369 & 0.382 & 0.247 & 0.31 \\
\hline Schwarz criterion & -3.10 & -3.08 & -3.15 & -2.91 \\
\hline Exogeneity test $p^{2}$ & 0.13 & 0.08 & 0.39 & 0.34 \\
\hline Homosk. $\mathrm{p}^{3}$ & 0.00 & 0.00 & 0.00 & 0.04 \\
\hline Joint $\operatorname{sig} \mathrm{p}^{4}$ & NA & 0.00 & 0.02 & 0.07 \\
\hline No. of parameters & 63 & 64 & 64 & 65 \\
\hline
\end{tabular}

Robust standard errors in parentheses. State and year effects included but not reported.* Significant at $10 \%$; ** significant at $5 \% ; * * *$ significant at $1 \%$.

1. Test of over-identifying restrictions. Probability at which we reject the null hypothesis that the excluded instruments are uncorrelated with the error term, and correctly excluded from the estimated equation.

2. Regression based Hausman specification test for the endogeneity of the variables marked with a " $\dagger$ ”. Probability value at which we reject the consistency and efficiency of OLS.

3. Pagan-Hall homoskedasticity test using the fitted value of the dependent variable.

4. Probability value of joint test of significance of $(1(C)$,Prohib_corp_union) in $(2),(1(C), 1(C) * \ln C)$ in (3), of $(1(C), 1(C) * \ln C$ terms) in (4).

$\ddagger$ Can't reject the exogeneity at $\mathrm{p}<0.83$ 
Table 4

First stage regressions for the regressions in Table 3

\begin{tabular}{|c|c|c|c|c|c|}
\hline Specification & $(1)$ & (2) & (3) & (4) & $(5)$ \\
\hline Dependent variable & $1(C)$ & $1(C)$ & $1(C) * \ln C$ & $1(C) *(\ln C)^{2}$ & $1(C) *(\ln C)^{3}$ \\
\hline \multirow[t]{2}{*}{ Lnpop } & $1.212 * * *$ & $1.093 * *$ & $11.508 * * *$ & $107.995 * * *$ & $1,006 * * *$ \\
\hline & $(0.466)$ & $(0.461)$ & $(3.879)$ & $(33.659)$ & $(299.6)$ \\
\hline \multirow[t]{2}{*}{ lny_capita } & 0.691 & 0.578 & 7.235 & 72.099 & $697.8 *$ \\
\hline & $(0.629)$ & $(0.622)$ & $(5.242)$ & $(45.483)$ & $(404.8)$ \\
\hline \multirow[t]{2}{*}{ hhi $[\lambda]$} & $75.981 *$ & 69.422 & 526.80 & 3,681 & 25,919 \\
\hline & $(45.012)$ & $(44.481)$ & $(375.05)$ & $(3,254)$ & $(28,964)$ \\
\hline \multirow[t]{2}{*}{ hhi squared } & -453.315 & -427.95 & $-2,948.5$ & $-18,677$ & $-112,449$ \\
\hline & $(482.316)$ & $(476.15)$ & $(4,018.7)$ & $(34,869)$ & $(310,358)$ \\
\hline \multirow[t]{2}{*}{ reg_con $[c]$} & 5.087 & 7.138 & 37.593 & 325.361 & $3,136.84$ \\
\hline & $(8.938)$ & $(8.847)$ & $(74.471)$ & $(646.173)$ & $(5,751.30)$ \\
\hline \multirow[t]{2}{*}{ ln voter info $[a]$} & -0.682 & -0.568 & $-8.026 * *$ & $-83.99 * *$ & $-830.90 * * *$ \\
\hline & $(0.480)$ & $(0.476)$ & $(4.004)$ & $(34.74)$ & $(309.19)$ \\
\hline \multirow[t]{2}{*}{ lny_taxes } & -0.034 & 0.05 & -0.882 & -10.916 & -111.15 \\
\hline & $(0.277)$ & $(0.275)$ & $(2.312)$ & $(20.059)$ & $(178.54)$ \\
\hline \multirow[t]{2}{*}{ dem 1} & -0.646 & -0.492 & -7.024 & -70.954 & -686.62 \\
\hline & $(0.894)$ & $(0.884)$ & $(7.450)$ & $(64.643)$ & $(575.36)$ \\
\hline \multirow[t]{2}{*}{ dem1sq } & 0.305 & 0.125 & 4.096 & 46.411 & 485.01 \\
\hline & $(0.711)$ & $(0.704)$ & $(5.923)$ & $(51.396)$ & $(457.45)$ \\
\hline \multirow[t]{2}{*}{ Chdem1 } & $0.831 * * *$ & $0.850 * * *$ & $7.028 * * *$ & $59.845 * * *$ & $512.06 * * *$ \\
\hline & $(0.300)$ & $(0.296)$ & $(2.502)$ & $(21.707)$ & $(193.20)$ \\
\hline \multirow[t]{2}{*}{ Chdem1sq } & -0.462 & -0.741 & -13.634 & -186.705 & $-2,121.7 *$ \\
\hline & $(1.899)$ & $(1.877)$ & $(15.826)$ & $(137.323)$ & $(1,222.3)$ \\
\hline \multirow[t]{2}{*}{ Demgov } & $-0.086^{* *}$ & $-0.088 * *$ & $-0.908 * * *$ & $-8.989 * * *$ & $-85.955 * * *$ \\
\hline & $(0.039)$ & $(0.038)$ & $(0.322)$ & $(2.798)$ & $(24.904)$ \\
\hline \multirow[t]{2}{*}{ Chdemgov } & 0.021 & 0.024 & 0.19 & 1.658 & 14.083 \\
\hline & $(0.038)$ & $(0.038)$ & $(0.319)$ & $(2.764)$ & $(24.601)$ \\
\hline \multirow[t]{2}{*}{ chdemgovxchdem1 } & $-1.276^{*}$ & $-1.270 *$ & $-12.346^{* *}$ & $-117.3 * *$ & $-1,102.8 * *$ \\
\hline & $(0.670)$ & $(0.661)$ & $(5.583)$ & $(48.44)$ & $(431.18)$ \\
\hline \multirow[t]{2}{*}{ Initcliberal } & 0.005 & $0.007 *$ & 0.05 & 0.475 & $4.453 *$ \\
\hline & $(0.004)$ & $(0.004)$ & $(0.034)$ & $(0.295)$ & $(2.622)$ \\
\hline \multirow[t]{2}{*}{ cit6099 } & $-0.007 * *$ & $-0.007 * *$ & $-0.060 * *$ & $-0.526^{* *}$ & $-4.646 * *$ \\
\hline & $(0.003)$ & $(0.003)$ & $(0.028)$ & $(0.245)$ & $(2.185)$ \\
\hline Prohibit & & $\begin{array}{l}0.146^{* * *} \\
(0.048)\end{array}$ & & & \\
\hline Observations & 391 & 391 & 391 & 391 & 391 \\
\hline R-squared & 0.32 & 0.34 & 0.32 & 0.32 & 0.31 \\
\hline F-test $p^{1}$ & 0.00 & 0.00 & 0.00 & 0.00 & 0.00 \\
\hline
\end{tabular}

Standard errors in parentheses. State and year effects included but not reported. * Significant at $10 \%$; ** significant at $5 \%$; *** significant at $1 \%$. ${ }^{\ddagger}$ Instruments tested for exogeneity, see $\mathrm{C}$-stat in table 1 .

In this table column 1 corresponds to the first stage regression of Table 3, column 1. Column 2 corresponds to the first stage of Table 3, column2. The first stages of Table 3, column 3 are the columns 1 and 3 of this table. The first stages of Table 3, column 4 are columns 1, 3, and 4 of this table.

1. P-value of the F-test of joint significance of the instruments in first-stage regression 
Table 5

Marginal effect of finance laws on the number of PACs

\begin{tabular}{|c|c|c|c|c|c|}
\hline \multirow[b]{2}{*}{ State } & \multirow[b]{2}{*}{ cap $(\$)$} & \multicolumn{4}{|c|}{$\partial \mathrm{E}(\ln n \mid \ln C) / \partial 1(C)^{1}$} \\
\hline & & $(1)$ & $(2$ & $(1 \mathrm{r}$ & $(2 r)$ \\
\hline $\mathrm{OR}^{2 \dagger}$ & 200 & & & & \\
\hline $\mathrm{ME}$ & 500 & & & & \\
\hline $\mathrm{MO}^{2 \dagger}$ & 550 & & & & \\
\hline $\mathrm{MN}$ & 600 & & & & \\
\hline $\mathrm{CT}$ & 1000 & 0.017 & 0.035 & 0.024 & 0.052 \\
\hline FL & 1000 & & & & \\
\hline $\mathrm{KS}$ & 1000 & & & & \\
\hline $\mathrm{MA}^{\dagger}$ & 1000 & & & & \\
\hline MI & 1000 & & & & \\
\hline MT & 1000 & & & & \\
\hline WI & 1000 & & & & \\
\hline $\mathrm{DE}$ & 1200 & & & & \\
\hline $\mathrm{WA}^{\dagger}$ & 1200 & & & & \\
\hline $\mathrm{AK}$ & 2000 & 0.047 & 0.050 & $0.048 *$ & 0.046 \\
\hline AR & 2000 & & & & \\
\hline HI & 2000 & & & & \\
\hline $\mathrm{KY}^{\dagger}$ & 2000 & & & & \\
\hline $\mathrm{RI}^{\dagger}$ & 2000 & & & & \\
\hline $\mathrm{SC}^{\dagger}$ & 2000 & & & & \\
\hline WV & 2000 & & & & \\
\hline $\mathrm{GA}^{\dagger}$ & 3000 & $0.064 * *$ & $0.058 *$ & $0.063 * *$ & 0.043 \\
\hline $\mathrm{A} Z^{\dagger}$ & 3020 & $* *$ & $*$ & $* *$ & \\
\hline VT & 4000 & $0.076 * * *$ & $0.064 * *$ & $0.073 * * *$ & 0.047 \\
\hline $\mathrm{LA}^{\dagger}$ & 5000 & $* * *$ & $* * *$ & $* * *$ & $*$ \\
\hline $\mathrm{OH}^{\dagger}$ & 5000 & $* * *$ & $* * *$ & $* * *$ & $*$ \\
\hline $\mathrm{MD}^{\dagger}$ & 6000 & $* * *$ & $* * *$ & $* * *$ & $*$ \\
\hline $\mathrm{NY}^{\dagger}$ & 6200 & $* * *$ & $* * *$ & $* * *$ & $*$ \\
\hline $\mathrm{NC}$ & 8000 & $0.11 * * *$ & $0.09 * * *$ & $0.10 * * *$ & $0.086 * * *$ \\
\hline $\mathrm{ID}^{\dagger}$ & 10000 & $* * *$ & $* * *$ & $* * *$ & $* * *$ \\
\hline $\mathrm{NH}$ & 10000 & $* * *$ & $* * *$ & $* * *$ & $* * *$ \\
\hline $\mathrm{NV}^{\dagger}$ & 10000 & $* * *$ & $* * *$ & $* * *$ & $* * *$ \\
\hline $\mathrm{OK}$ & 10000 & $* * *$ & $* * *$ & $* * *$ & $* * *$ \\
\hline $\mathrm{TN}^{\dagger}$ & 10000 & $0.12 * * *$ & $0.10 * * *$ & $0.11 * * *$ & $0.11 * * *$ \\
\hline $\mathrm{NJ}^{\dagger}$ & 11800 & $* * *$ & $* * *$ & $* * *$ & $* * *$ \\
\hline $\mathrm{CO}^{\dagger}$ & 20000 & $* * *$ & $* * *$ & $* * *$ & $* * *$ \\
\hline $\mathrm{NE}^{\dagger}$ & 73000 & $0.20 * * *$ & $0.34 * * *$ & $0.18^{* * *}$ & $0.86 * * *$ \\
\hline
\end{tabular}

1. $\partial \mathrm{E}(\ln n \mid \ln C) / \partial 1(C)=\delta_{1}+\delta_{2} \ln C$ for (1) and (1r) and $\delta_{1}+\delta_{2} \ln C+\delta_{3}(\ln C)^{2}+\delta_{4}(\ln C)^{3}$ for (2) and (2r) in table $2 \mathrm{~b}$. The asterisks represent the level at which we can reject the null of $\partial \mathrm{E}(\ln n \mid \ln C) / \partial 1(C)=0$ using a Wald test. $10 \%(*)$; $5 \%(* *)$ and $1 \%(* * *)$. 2. OR had a limit only in 1996. MO had a limit in $1996(\$ 500)$ and $1998(\$ 550) .{ }^{\dagger}$ Denotes states that imposed limits after 1986. 
Table 6

Data description

\begin{tabular}{|c|c|c|}
\hline NAME & DESCRIPTION & SOURCE \\
\hline $\ln n_{\text {it }}$ & $\begin{array}{l}\text { Number of organizations from state } i \text { at } t \text { registered as } \\
\text { federal PACs }\end{array}$ & $\begin{array}{l}\text { Federal Election } \\
\text { Commission }\end{array}$ \\
\hline $1(C)$ & $\begin{array}{l}\text { State campaign finance law imposing limit on contributions } \\
\text { from state PACs }\end{array}$ & $\begin{array}{l}\text { Campaign Finance } \\
\text { Laws (FEC) }\end{array}$ \\
\hline $1(C)^{*} \ln C$ & $1(C) * \log (\$$ contribution limit $)$ & " " \\
\hline Prohib_corp_union & $\begin{array}{l}=1,2 \text { if state Prohib_corp_unions contributions from either } \\
\text { or both corporations and unions, otherwise zero }\end{array}$ & $" "$ \\
\hline Hhi $[\lambda]$ & $\begin{array}{l}\text { Herfindahl-Hirschman index calculated from the wage } \\
\text { employment in a state at the } 3 \text {-digit SIC code } \mathrm{k} . \\
\sum_{\mathrm{k}}\left(\mathrm{e}_{\mathrm{ikt}} \mathrm{l}_{\mathrm{ikt}} / \mathrm{e}_{\mathrm{it}} \mathrm{l}_{\mathrm{it}}\right)^{2}\end{array}$ & BEA \\
\hline \multirow[t]{3}{*}{ Reg_con $[c]$} & $\begin{array}{l}\text { Regional concentration index, calculated from wage } \\
\text { employment in a state at the } 3 \text {-digit SIC code } \mathrm{k}\end{array}$ & " " \\
\hline & $\Sigma_{\mathrm{k}}\left\{\mathrm{w}_{\mathrm{ikt}} * \operatorname{abs}\left(\left(\mathrm{e}_{\mathrm{ikt}} / \Sigma_{\mathrm{k}}\left(\mathrm{e}_{\mathrm{ikt}}\right)-\mathrm{POP}_{\mathrm{k}} / \Sigma_{\mathrm{k}} \mathrm{POP}_{\mathrm{kt}}\right)\right\}\right.$ & \\
\hline & $\mathrm{W}_{\mathrm{ikt}}=\mathrm{e}_{\mathrm{ikt} t} / \Sigma_{\mathrm{k}}\left(\mathrm{e}_{\mathrm{ikt}}\right)$ & \\
\hline Lny_taxes & Log(state government income taxes) & $"$ " \\
\hline $\begin{array}{l}\text { voter information } \\
{[a]}\end{array}$ & $\begin{array}{l}\text { National election study - transformed as described in the } \\
\text { text }\end{array}$ & National Election Study \\
\hline Lnpop & $\log ($ state population $)$ & $\begin{array}{l}\text { Statistical Abstract } \\
\text { of the United States }\end{array}$ \\
\hline Lny_capita & $\log ($ state income/capita) & $" "$ \\
\hline $\begin{array}{l}\operatorname{dem} 1 \\
\operatorname{dem} 1 \mathrm{sq}\end{array}$ & Share of seats held by Democrats in the state assembly & $\begin{array}{l}\text { Book of the States } \\
" " \prime\end{array}$ \\
\hline chdem 1 & Change in dem 1 & $" \prime$ \\
\hline Demgov & $=1$ if governorship is held by a democrat, 0 otherwise. & $"$ " \\
\hline chdemgov & Change in demgov & " " \\
\hline chdemgovxchdem1 & Chdemgov* dem 1 & $" \prime$ \\
\hline Initiative & $=1$ if state has an initiative process, 0 otherwise & $" "$ \\
\hline $\begin{array}{l}\text { Cit6099 } \\
\text { initcliberal }\end{array}$ & $\begin{array}{l}\text { Index of how liberal citizens are in state } i \text { at } t \\
\text { Initiative* cit6099 }\end{array}$ & ICPSR study 1208 \\
\hline
\end{tabular}


Figure 1

Equilibrium Contribution and Transfer with caps

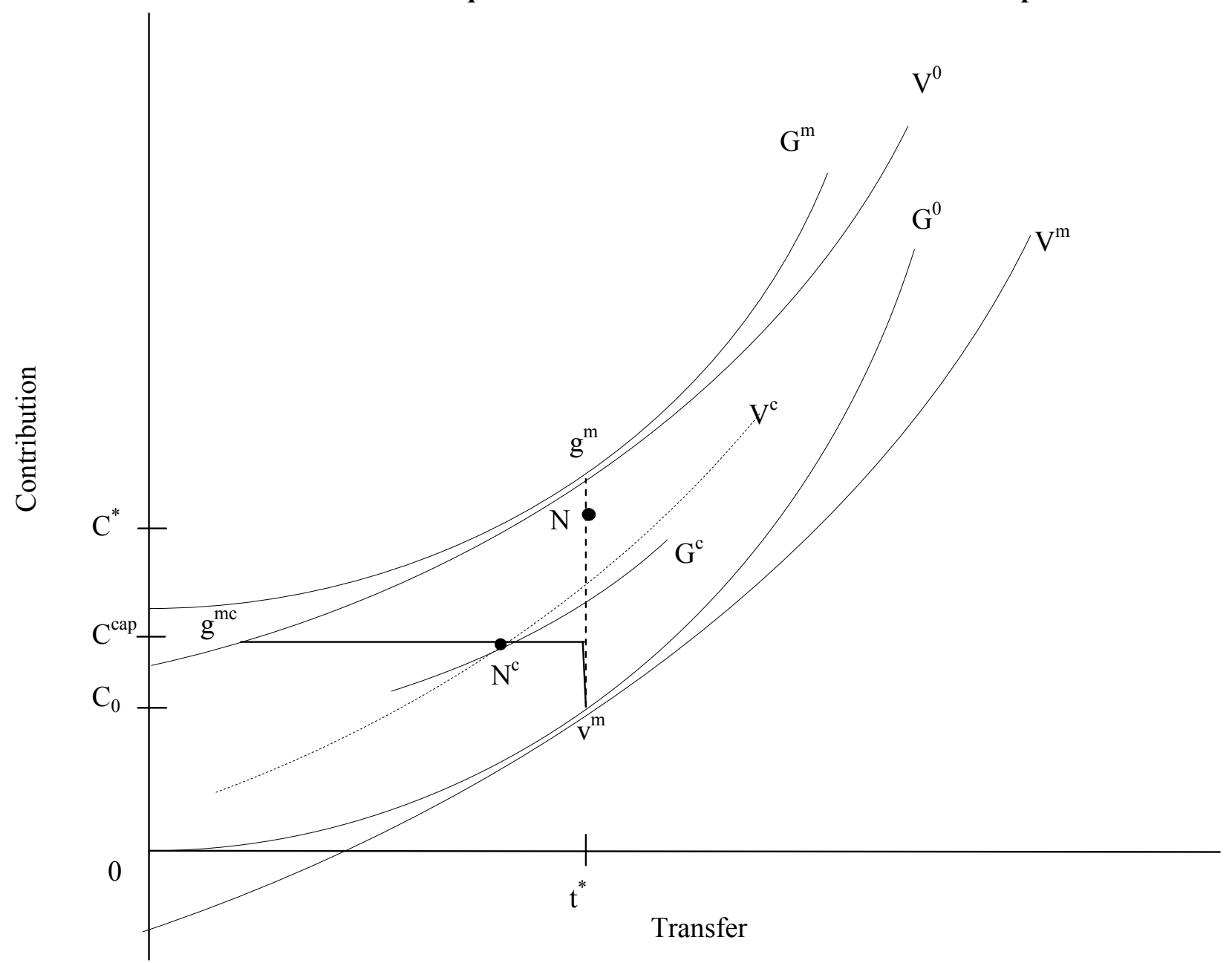




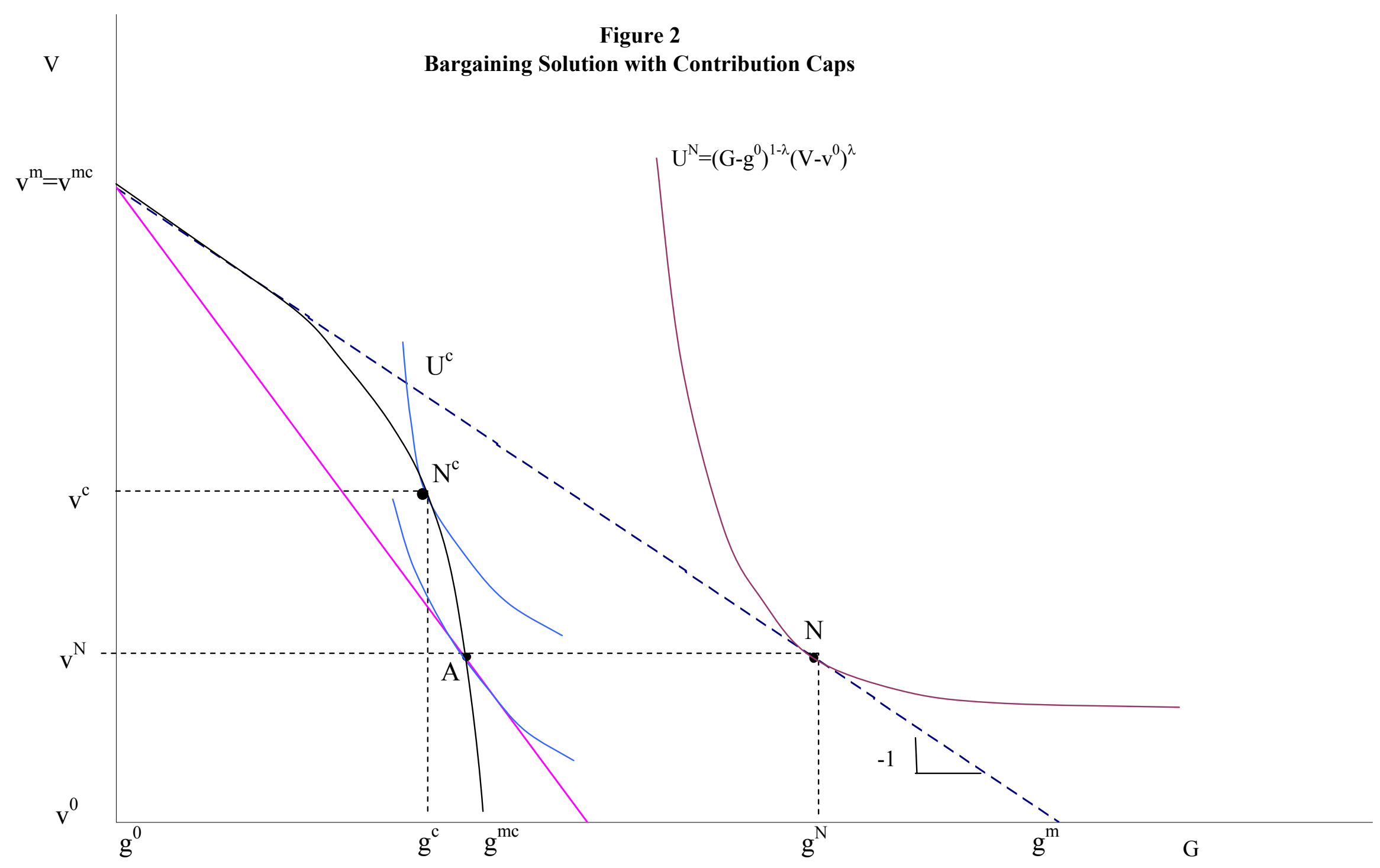

